\title{
PRECEDENTS, FUNDACIÓ I PRIMERS ANYS DEL MONESTIR DE VALLBONA \\ (1154-1185)
}

\author{
JOSEP MARIA SANS I TRAVÉ \\ Arxiu Nacional de Catalunya
}

\begin{abstract}
SUMARI
1. Estat de la qüestió.- 2. El fundador de Vallbona: l'eremita Ramon.- 3. La donació de Ramon Berenguer IV de Sòrboles a Ramon de Vallbona i els seus companys eremites (26 de maig de 1157). - 4. L'eremitori de Vallbona.- 5. Ramon de Cervera, benefactor de la primera comunitat eremítica de Vallbona.- 6. L'organització de nous centres eremítics per part de Ramon de Vallbona.- 7. L'alienació de Sòrboles a Poblet ( $1^{r}$ d'abril de 1171).- 8. La incorporació de Vallbona a l'Orde del Cister (1171).- 9. La distribució dels eremites vallbonencs i la sol-licitud de monges cistercenques a Tulebras (Navarra).- 10. El testament de Ramon de Vallbona (8 d'abril de 1176) i les seves conseqüències.- 11. El trasillat de l'abadessa Òria de Colobres a Vallbona.- 12. La visita $i$ el sojorn dels monarques catalans Alfons i Sança a Vallbona (febrer-març de 1178).- 13. La donació d'una torre i d'unes terres al terme de la ciutat de Lleida (26 de març de 1178) i el projecte de la fundació d'un nou monestir.- 14. L'obra de l'abadessa Òria.- 15. La col-laboració de Berenguera de Cervera o d'Anglesola.
\end{abstract}

\section{ESTAT DE LA QÜESTIÓ}

Haig d'avançar, d'entrada, que qualsevol investigador que pretengui endinsar-se en el passat històric de Vallbona es trobarà amb una dificultat insuperable: la manca d'informació suficient, més pronunciada a mesura que

"Anuario de Estudios Medievales". 29 (1999) 
l'enfocament s'atança als seus orígens. Aquest estorb ja el varen patir el Pare Pasqual a començament del segle XIX i el P. Jaume Ripoll que edità anotada el 1837 la Carta al Marquès de Capmany, del primer, i continua òbviament en l'actualitat. El P. Pasqual a l'inici del seu treball ja feia notar que en el archivo del real monasterio de Vallbona ... han perseverado muy pocas memorias de los principios y fundación del mismo monasterio ${ }^{1}$. Només amb un cop d'ull als regestos documentals recollits als Índex vell i nou conservats a l'arxiu del monestir n'hi ha prou per adonar-se'n de la gran quantitat de pergamins, que correspondrien a la seva època més antiga, que en el decurs del temps han anat desapareixent de l'arxiu del cenobi.

Si ens fixem en la realitat actual, trobarem que del monestir i del seu fundador Ramon de Vallbona, entre el 1154 - la primera referència documental al lloc de Vallbona, per bé que tradicionalment s'ha près el 1153 , per no haver fet la reducció convenient de l'any de l'Encarnació-2 i el 1190 hom disposa de trenta-sis instruments publicats, dels quals només dinou aporten una informació suficient ${ }^{3}$.

'Carta del P. D. Jaime PASQUAL, canónigo premostratense de Bellpuig de las Avellanas al M.I.S. Marqués de Capmany o sea Recopilación de noticias y documentos los mas intereseantes de la fundacion y de los fundadores del real y antiguo monasterio de señoras religiosas cistercienses de Sta. Maria de Vallbona en Cataluña, sito en el arzobispado de Tarragona y territorio de Urgel, Publicada con notas y observaciones D. J. R.V., Barcelona, Imprenta de Valentin Torras, 1837, p. 5.

'Joan Josep PIQUer I Jover, Abaciologi de Santa Maria de Vallbona (1153-1977). Santes Creus, 1978, pp. 30-31.

${ }^{3}$ Els instruments més o menys sencers són:

1.- Donació de Ramon Berenguer IV del lloc de Sòrboles als tres anacoretes (26 de maig de 1157)

2.- Donació de Ramon de Cervera i altres nobles a Santa Maria de Vallbona i a l'eremita Ramon de l'alou que tenen a la vall de Vallbona (20 de juliol de 1157)

3.- Donació de Pere d'Aguda, anomenat Valdària, i dels seus del lloc anomenat Vallbona, a Santa Maria, a fra Ramon l'eremita, al prevere Pere, a Ramon Duran $i$ als altres frares que serveixen a Déu en el lloc de Vallbona (9 d'octubre de 1157).

4.- Donació de Ramon de Cervera i la seva dona Ponceta del castell Colobrer i l'església de Sant Joan de l'esmentat castell amb una parellada en alou a Santa Maria de Vallbona i al Sant Esperit $i$ als habitants que hi ha $i$ en l'esdevenidor hi aniran (18 de juliol de 1164)

5.- Donació de Pere d'Aguda, juntament amb els seus, d'un hort a Sant Martí de Maldà, situat al costat del molí de Pere Company, i l'alou de Sant Llorenç, a favor del lloc de Santa Maria de Vallbona $i$ dels frares $i$ sorores que hi ha o hi aniran (26 de juny de 1169).

6.- Donació de Berenguer de Cardona de la seva dominicatura de Vilamanyanor a favor del monestir de Santa Maria de Vallbona, de l'eremita Ramon, servent de Déu, i de les monges que hi serveixen a Déu. Rep en compensació 500 sous barcelonesos (25 d'agost de 1174).

7.- Alfons I dóna a la casa de Vallbona i a Beatriu la plaça del canatarer Boacar i dels seus nebots que actualment és de Ponç Panicer, amb la condició que sigui totalment francá de qualsevol cens i usatge (octubre de 1174). 
Si comparem aquestes xifres amb les corresponents al monestir de Poblet, per posar un exemple proper geogràficament, ens adonarem de la migradesa documental de Vallbona. Així, del monestir de la Conca, des de gener de 1150 - data de la donació de l'Hort de Poblet a l'abat Sanç de Fontfreda-, fins al 31 d'agost de 1177, hom disposa de 477 instruments.

És, doncs, per aquest motiu - la manca d'informació suficient- que la major part dels autors que s'han aplicat a esbrinar la història dels inicis del nostre monestir han declarat unànimement la obscuritat dels orígens $\mathrm{i}$ primers anys del cenobi urgellenc.

Els inicis del nostre monestir foren ja objecte d'estudi del P. Pasqual a començament del segle passat, tot $\mathrm{i}$ que el que més interessava a aquest

8. - Donació d'una peça d'alou situada a Anglesola, al lloc anomenat Llagostera, feta per Arsenda, muller d'Isarn, amb motiu de professar fidelitat, castitat $\mathrm{i}$ obediència, segons l'orde de sant Benet, a Santa Maria de Vallbona, en mans de Ramon, eremita i servent de Déu, del prevere Pere $\mathrm{i}$ dels altres fares $\mathrm{i}$ fraresses (1175).

9.-Testament de l'eremita Ramon de Vallbona (8 d'abril de 1176)

10. - Concessió per part d'Alfons I al monestir de Santa Maria de Vallbona i a l'abadessa Òria de l'honor de Rofea, dins dels termes de la ciutat de Lleida (març de 1177, Lleida).

11.- Concessió del privilegi d'immunitat reial d'Alfons I a favor de l'abadessa Ôria i de les altres fraresses del monestir de Santa Maria de Vallbona, que afecta a les propietats, cases. cabanes, homes i animals de l'esmentat monestir (abril de 1177).

12.- Ramon de Torroja i la seva esposa Gaia donen al monestir de Santa Maria de Vallbona i a la seva abadessa Òria una terra situada en el terme de Barbens (27 de novembre de 1177).

13.- Adquisició per 500 sous barcelonesos del lloc de Vallbona per la reina Sança $i$ concessió del mateix lloc a les monges perquè hi edifiquin una casa on duguin vida regular (febrer de 1178?)

14.- Concessió d'Alfons I a favor de la casa de Santa Maria de Vallbona, de la seva abadessa Ôria i de les germanes que hi serveixen a Déu, d'una torre situada a la ciutat de Lleida perquè hi edifiquin una abadia femenina cistercenca ( 26 de març de 1178, Saragossa)

15.- Donació de Barnat de Caldes d'un honor que té a la ciutat de Lleida, a favor de Santa Maria de Vallbona i de les fraresses que alli hi ha, en mans de l'abadessa Òria Ramirez (22 d'agost de 1178).

16. - Concessió de Guillem d'Aguda a favor de Santa Maria de Vallbona, de l'abadessa Sandina i del convent de monges de l'esmentat lloc de tot el que té a Vilamanyanor i el seu terme, és a dir, molins, delmes, censos, usatges $\mathrm{i}$ diumenges, $i$ a més, tots els drets que té en el terme de Vallbona $i$ els molins del Vinyet $i$ un diumenge en el terme de Sant Martí, amb motiu de l'ingrés de la seva filla Romana al monestir (abril de 1180).

17. - Concessió de Pere de Bellvís a favor dẹl convent de Santa Maria de Vallbona i dels seus monjos i fraresses, en mans de l'abadessa Òria Ramirez, de Berenguera de Cervera, de Berenguera d'Odena i de totes les fraresses que hi ha servint a Déu, de tots els drets que té en el castell de Llorenç, amb motiu d'ingressar en la confraternitat del monestir ( 8 de febrer de 1182).

18. - Concessió per part d'Alfons I de la torre de Serralada, amb tres jovades de terra, situada en el terme de la ciutat de Lleida, a favor del monestir de Vallbona $i$ de la seva abadessa Ôria Ramirez (setembre de 1183, Lleida).

19.- Donació de Guillelma perquè sigui monja del monestir de Vallbona, feta per la seva mare Jovària $i$ el seu germà Guillem de Tàrrega, en mans de l'abadessa Òria, de Berenguera de Cervera $i$ de tot el convent del dit cenobi (13 de febrer de 1185). 
erudit eclesiàstic era el paper desenvolupat per Berenguera de Cervera en la singladura del cenobi, tal com ell mateix afirma: “... y por consiguiente sean muy escasas las que se conservan de Dna Berenguela de Cervera que son el objeto de los deseos de V.S. y sobre el cual ha tenido V.S. la bondad de pedirme alguna luz"4. Malgrat això, el premostratenc de les Avellanes dedicà unes pàgines al fundador i també als primers anys del monestir ${ }^{5}$. Aquest mateix autor s'ocupa de la fundació del cenobi en el seu famós Llibre Verd que es conserva a l'Arxiu del Monestir de Santa Maria de Vallbona i que redactà a instàncies de l'abadessa Maria Teresa de Riquer i de Sabater per tal de donar resposta als cinc punts de l'interrogatori formulat pel Vicari General cistercenc. Durant tres mesos el P. Pasqual treballà a l'arxiu del monestir recollint informació $i$ transcrivint documents que després aprofità per respondre a les cinc preguntes del qüestionari i per elaborar el Llibre Verd que, a més de les esmentades respostes, recull abaciologis, la vida de Ramon de Vallbona i altres documents importants del monestir ${ }^{6}$.

Aquestes cinc preguntes del qüestionari es referien al temps en què es fundà el monestir, als seus fundadors, si havia estat redotat pels monarques o bé per particulars en el cas que hagués sofert una notable crisi econòmica, com es duien a terme les eleccions de les abadesses des de la seva fundació fins el 1616 en què ingressà a la Congregació $i$, finalment, si en algun moment els papes o els reis havien intentat o obtingut la provisió de l'abadia'.

Les respostes a totes aquestes preguntes exigiren al P. Pasqual una anàlisi dels orígens del monestir i de la personalitat del fundador ${ }^{8}$. Un resum de les seves conclusions foren precisament publicades, després de la seva

\footnotetext{
${ }^{4} J a i m e$ PASQual, Carta al Marques de Capmay, obra cit., p. 5.

5Jaime Pasqual, Carta al Marqués de Capmany, obra cit., pp. 5-16.

${ }^{6}$ Gener Gonzalvo I Bou, Pròleg a la Carta al Marqués de Capmany, 2a Edició, Consell Comarcal de l'Urgell, s.a., pp. 3-4.

${ }^{7}$ Isabel NavascuÉs, Carme Bello, Gener Gonzalvo, Inventari de l'Arxiu del monestir de Santa Maria de Vallbona, Departament de Cultura, Barcelona, 1992, pàg. 364: Joan Josep PIQUER I JOVER, Abaciologi de Vallbona (1153-1977), Santes Creus, 1978, pp. 328-330.

${ }^{8} \mathrm{El}$ títol complert d'aquest còdex és el següent: «Llibre Vert. Respuesta a los cinco interrogatorios del Sr. Vicario General Cisterciense que, a solicitación de la mui Ilustre Señora Doña Theresa de Riquer y de Sabater, abadesa, y de su real monasterio de Vallbona, ha trabajado, después de examinados los antiguos instrumentos de su Archivo, el Dr. en derechos Don Jayme Pasqual, canónigo premostratense y exabad del real Monasterio de Bellpuig de las Avellanas. Año MDCCC».
} 
mort, en la ja esmentada Carta al Marqués de Campmany pel seu amic i col·lega el canonge Ripoll el 1837.

La meva aportació diferirà en alguns aspectes de les conclusions a les quals ha arribat l'emèrit historiador de Vallbona, Josep-Joan Piquer i Jover, a les primeres pàgines de l'Abaciologi, ja que a través d'una relectura dels documents que va utilitzar i d'altres exhaurits amb posterioritat a la publicació del seu treball em permetré rectificar algunes de les seves afirmacions, ja sigui rebutjant episodis - com el de la famosa Decretal del Metus, promulgada el 1180 per Alexandre III, que de cap manera respongué a un fet esdevingut a la comunitat de Colobres, com assenyalà Piquer, sinó a Tulebras, el primer monestir cistercenc femení de la península ibèrica ${ }^{9}-$ ja sigui canviant datacions de documents, ja que tots els datats entre el primer de gener i el vint-i-quatre de març pel sistema de la Encarnació no han estat reduits al corresponent any de l'era comuna.

Quatre seran els eixos d'aquest estudi, a través de l'exposició dels quals s'entendrà, a criteri meu, l'origen i el procés seguit en els primers temps pel monestir de Vallbona: el fundador i les seves activitats eremítiques; la incorporació de Vallbona a l'orde del Cister; el testament de Ramon de Vallbona i les seves conseqüències; el trasllat de l'abadessa Òria de Colobres a Vallbona i la consolidació de la comunitat vallbonenca.

\section{El fundador DE VALlbona: L'EREMita RAMON}

La figura de Ramon de Vallbona ha estat ja tractada en la historiografia vallbonenca, especialment pel P. Jaume Pasqual en la seva Carta al Marqués de Campmany ${ }^{10}$ per Josep Lladonosa, en la seva síntesi sobre la història del monestir amb motiu de la celebració l'any 1957 del vuitè centenari de la seva fundació" ${ }^{\prime}$, per Agustí Altisent, qui ha dedicat una interessant estudi a aquest personatge, arran de la seva vinculació amb Poblet

\footnotetext{
"Josep Joan PIQUeR I JOver. La Decretal del "metus" del cenobi de Colobres. Contribució a l'estudi dels origens monàstics de la serralada del Tallat, "BAT", Ëpoca IV, fasc. 133-140. anys 1976-77, pp. 109-132.

${ }^{10}$ Jaime PASQual, Carta al Marqués de Capmany, Barcelona, 1837, pp. 6-8, 10-13, 15, 2630, núms. 2-7, 11-12,14, 18. 33-37.

"José Lladonosa Pujol, El Real Monasterio de Santa Maria de Vallbona lOctavo Centenario de su fundación), 1157-1957, Lérida, 1957, pp. 15-20.
} 
i la fundació de l'eremitori de Poboleda ${ }^{12}$, per l'emèrit historiador del monestir Josep Joan Piquer i Jover en la seva obra Abaciologi de Santa Maria de Vallbona ${ }^{13}$ i per jo mateix en el meu estudi sobre el santuari del Tallat $^{14}$.

A grans trets, a banda de la historiografia, sobre Ramon de Vallbona hom disposa de dos tipus de fonts que permeten esboçar els trets característics de la seva existència: els documents coetanis i una "Vita" o biografia del fundador, de contingut hagiogràfic, escrita bastants anys després de la seva mort que, però, pel fet d'haver-se redactat en el propi monestir deuria recollir la tradició que obrava allí sobre el personatge.

El fundador del futur monestir de Vallbona fou un tal Ramon, que en els documents compresos entre el 20 de juliol de 1157 i el 8 d'abril de 1176 - data del seu testament-, apareix amb l'específic d'eremita al començament, i a partir de 1164 , amb els determinants d'"eremita de Vallbona" o simplement "Ramon de Vallbona". Tot i que la "Vita", tant en la seva versió llatina, continguda en el Còdex de Blanca d'Anglesola - probablement de final del segle XIII- ${ }^{15} \mathrm{com}$ en la seva versió catalana - recollida en el llibre anomenat l'Aranzel, de la segona meitat del s. $\mathrm{XVII}^{16}$, i també en el Ms, 239 de la Biblioteca Nacional de París, procedent probablement de la Biblioteca de Pere de Marca i titulat De la miraculosa fundació del sagrat monestir de Nostra Senyora de Vallbona, del Ordre de Cistells $-{ }^{17}$, el facin "oriundus" o "natural" d'Anglesola, no hem trobat cap document coetani que pugui justificar aquest aspecte que s'hauria introduït al text llatí de la "Vita" amb posterioritat a la redacció original, com ja va fer notar el P. Jaume Pasqual, per bé que no com un afegit fals

\footnotetext{
${ }^{12}$ Agustí Altisent, Ramon de Vallbona i l'eremitori de Poboleda, "Studia Monastica". 10 (1968), pp. 141-149.

${ }^{13}$ Josep Joan PIQUeR I JOVER, Abaciologi de Vallbona (1153-1977), Fundació Roger de Belfort, Santes Creus, 1978, pàgs. 30-38.

${ }^{14 J o s e p ~ M a r i a ~ S A N S ~ I ~ T R A v E ́, ~ H i s t o ̀ r i a ~ d e l ~ T a l l a t, ~ L l e i d a, ~ V i r g i l i ~ i ~ P a g e ̀ s, ~ 1986, ~ p p . ~ 40-53 . ~}$

${ }^{15}$ Copiada en el "Llibre Vert" pel P. Jaume Pasqual (Vegeu Llibre Vert, pàgs. 135-140, s.n.) Hom en pot trobar una edició a Josep Joan PIQUER I JOVER, Cartulari de Vallbona (11571665), "Boletín de la Real Academia de Buenas Letras de Barcelona", XXXVII (1977-78), doc. 11 , pp. $81-83$.

${ }^{16}$ Editada per Mn. Ramon Bergadà (vegeu Ramon BERGADÀ, Disertación histórica sobre el origen del pueblo de Vallbona de las Monjas y su devoción a la Stma. Virgen del pueblo de Tallat, Lleida, Academia Mariana, 1906, pp. 100-106.

${ }^{17}$ Jordi Rovira I SORIaNo, Els origens de Vallbona de les Monges en un manuscrit de la Biblioteca Nacional de París, Tarragona, Paratge Tarragoni, 1991.
} 
sinó degut a un descuit de l'escrivà que la copià al còdex de Blanca d'Anglesola $^{18}$. Per a Piquer, però, l'afegit de Angularia oriundus respondria a l'interès d'algunes de les abadesses de la casa d'Anglesola del segle XIV -Berenguera (1348-1377), Sibil·la (1377-1379) o Saurena (1379-1392)-per prestigiar el seu propi llinatge ${ }^{19}$. Certament que coincidim amb aquesta darrera opinió, expressant també, d'altra banda, la possibilitat que la correcció pretengués un origen més noble de la persona del fundador ja que casos com aquest, de cercar els orígens d'institucions en personatges de la noblesa, es donaren sovint a l'època medieval.

\section{LA DONACIÓ DE RAMON BERENGUER IV DE SÒRBOLES A RAMON DE VALLBONA I ELS SEUS COMPANYS EREMITES (26 DE MAIG DE 1157)}

La primera notícia documental que disposem de Ramon de Vallbona és del 1157, i precisament no fa referència al centre eremític de la banda septentrional del Tallat, sinó a les Garrigues. En efecte, és quan el 26 de maig del dit any, Ramon Berenguer IV, estant a la ciutat de Tortosa, concedí el lloc de Sòrboles, situat en el territori de Siurana - l'actual Pobla de Cèrvoles-, a Déu i a Santa Maria perquè s'hi bastís una abadia sota la regla i obediència de Sant Benet ${ }^{20}$. Amb aquesta finalitat el comte donava la terra que poguessin conrear anualment sis parells de bous, a més de l'aigua del riu Set que fos necessària per regar els horts i altres conreus. Finalment, els frares del futur monestir restaven facultats per bastir un molí aprofitant l'esmentat corrent.

Els beneficiaris de la donació eren tres personatges que deurien ser prou coneguts en aquella contrada: el venerable Ramon Homededéu, l'eremita Ramon - "humil frare d'aquest lloc"-i Guillem.

\footnotetext{
${ }^{18}$ Jayme PASQual, Carta al Marqués de Capmany, pp. 12-13. La mateixa opinió segueix l'editor d'aquesta obra el P. Ripoll i Vilamajor, a l'apèndix (Vegeu Carta al Marqués de Capmany), p. 44. 37.

19Josep Joan PIQUer i Jover, Abaciologi de Vallbona (1153-1977), Santes Creus, 1978, p.

${ }^{20}$ Agustí Altisent, Diplomatari de Santa Maria de Poblet. Volum I. Anys 960-1177, Generalitat de Catalunya, Barcelona, 1993, doc. 199, pp. 168-169.
} 
Aquest document, poc valorat per la historiografia vallbonenca, té una importància cabdal per a conèixer els projectes de colonització d'aquesta banda de les Garrigues per part de Ramon Berenguer IV i per entendre l'actuació dels grups d'anacoretes que a mitjan segle XII habitaven les contrades feia poc conquerides.

La intenció del comte barceloní en concedir Sòrboles als tres ermitans s'ha de relacionar directament amb la política de colonització de la banda ponentina del territori català, especialment la gran bossa compresa entre Tortosa i Lleida i alliberada definitivament de sarraïns després que el 1153/1154 s'ocupés el darrer reducte de Siurana.

La donació de Ramon Berenguer IV s'emmarca, doncs, en el conjunt d'iniciatives colonitzadores dutes a terme a mitjan segle XII que tenien per objectiu la posada en conreu de les terres recentment conquerides per tal d'assegurar-ne la seva explotació mitjançant l'assentament de nous pobladors. Iniciatives que en alguns llocs realitzaren nobles, com els Cervera, que concretaren la seva actuació a la comarca dels Comalats i al lloc més occidental de l'Espluga de Francolí, on els germans Ramon i Ponç, a partir de 1150 desenvoluparen una tasca importantíssima d'atracció de repobladors $^{21}$, sense descurar altres llocs de la contrada com ara el Tallat o Belltall $^{22}$. D'altres actuacions foren dirigides directament pel mateix comte, com els casos de l'Espluga Calba, el 1148, Tarrés i Milmanda el 1149, Vimbodí el 1151, Vinaixa el 1151 i 1152 i Montblanc pels anys immediatament posteriors ${ }^{23}$.

Finalment, d'altres operacions colonitzadores, Ramon Berenguer IV les encomanà a monestirs, confiant que el dinamisme de les comunitats monàstiques representés un element de fixació cristià del territori i que esdevinguessin nuclis especialitzats d'explotació agrícola ${ }^{24}$. La donació de

\footnotetext{
${ }^{21}$ Agustí ALTISENT, Un poble de la Catalunya Nova els segles XI i XII. L'Espluga de Francoli de 1079 a 1200, "Anuario de Estudios Medievales", 3 (1966), pp. 131-213.

${ }^{22}$ Josep Maria SANS I TRavÉ, Pere de Queralt, primer feudatari de l'Espluga de Francolí (1150-1166), "Universitas Tarraconensis", 2 (1977-78), pp. 25-52; Josep Maria SANS I TRAVÉ, La carta de franquicia de Belltall (19 de novembre de 1227), "Universitas Tarraconensis", 1 (1976), pp. 9-58.

${ }^{23}$ José M $\mathrm{M}^{\mathrm{a}}$ FONT RIUS, Cartas de población y franquicia de Catalunña, I. Textos, CSIC, Madrid-Barcelona, 1969, núm. 67, pp. 109-110, núm 71, pp. 115-116, núm. 72, pp. 117-118; núm. 88 , pp. 140-141; núms. 86 i 90 , pp. 138-139 i 142-143; núms. 98 i 99 , pp. 151-153 i 153-154; i pp.745747 (Montblanc); p. 754 (Milmanda); pp. $755-757$ (Vimbodí); p. 757 (Tarrés); p. 816 (Espluga Calba); pp. 816-817 (Vinaixa).

${ }^{24}$ Agustí Altisent, Història de Poblet, Abadia de Poblet, 1974, pp. 25-28.
} 
l'Hort de Poblet a l'abat Sanç de Fontfreda el 18 de gener de 1150 s'inseria, naturalment, en aquests plans del comte barceloní ${ }^{25}$, i el mateix hom pot afirmar de la donació de Sòrboles feta en favor de Ramon Homededéu, l'eremita Ramon i Guillem.

Això fa pensar, per consegüent, que Ramon Berenguer IV projectà la fundació de dos monestirs, relativament propers, en el camí de Tarragona a Lleida, al redós el primer de les muntanyes de Prades, i l'altre, més al nord-oest, a l'altra banda de la Serra d'en Llena. Així mateix, el primer respondria a iniciativa d'un altre monestir cistercenc, mentre que el segon hauria de ser benedictí i la seva fundació i organització era encomanada a tres promotors particulars vinculats al món eremític de la contrada.

Interessa ara, precisament, identificar en allò possible aquests tres promotors de la futura abadia benedictina. Del primer, Ramon Homededéu i del tercer Guillem no hem pogut trobar cap altre rastre en la documentació que hem consultat. El fet, però, que el document s'adreci a Ramon amb el qualificatiu de "venerabilis" i que aparegui com a primer relacionat suggereix la possibilitat que deuria tractar-se del més gran i del cap del grup.

Avanço la hipòtesi que aquesta colla es podria relacionar, d'alguna manera, amb el nucli eremític establert a la banda septentrional del terme de Poblet - recordem que precisament una de les fites de Vimbodí concedit el 30 de novembre de1151 als pobladors del lloc era la del "terme de les Ermites" 26 - abans que el lloc fos donat als cistercencs i que Ramon Berenguer per resarcir els anteriors anacoretes els oferís, amb la concessió de Sórboles, la possibilitat d'organitzar un nou monestir. És una possibilitat que no cal descartar i que arrodoneix el complex món dels eremites situats a la banda més llunyana i inhòspita de la frontera cristiana, on en el moment en que s'hi afincaren inicialment només trobaren la soledat del seu entorn.

\footnotetext{
${ }^{25}$ Agustí Altisent, Història de Poblet, Abadia de Poblet, 1974, pp. 28-32.

${ }^{26}$ Agustí Altisent, Diplomatari de Santa Maria de Poblet. Volum I. Anys 960-1177, Generalitat de Catalunya, Barcelona, 1993, doc. 143, pp. 129-130.
} 


\section{L'EREMITORI DE VALLBONA}

L'eremita Ramon, que rep la donació de Sòrboles juntament amb els altres dos companys, és el que ens interessa destacar en aquesta història perquè, com hem dit, ell serà després el fundador de Vallbona.

La primera pregunta que cal fer-nos és si l'eremita Ramon, abans d'aquesta donació comtal de Sòrboles, havia organitzat un o més centres eremítics a la banda septentrional de la Serra del Tallat, a les petites i tancades valls que baixen amb suavitat des del sector muntanyenc. La resposta hauria de ser positiva si acceptem que l'Índex vell de Vallbona enregistra una donació d'una sort de terra i l'elecció de sepultura en el lloc de Santa Maria de Vallbona feta per una tal Agnès el 28 de febrer de 1154, i que la historiografia presenta com el primer document conegut relatiu al nostre monestir ${ }^{27}$.

$\mathrm{Si}$ admetem com a correcta i verídica aquesta data resultaria que efectivament a mitjan segle XII o poc temps abans a Vallbona existia algun anacoreta, que en un principi sol, i després amb deixebles, duia una vida dedicada a la penitència i l'oració.

Tot i la credulitat que mereixen els textos hagiogràfics com el de la Vita beati Raimundi confessoris, aquest narra alguns aspectes que podrien donar una certa llum als moments inicials de l'activitat de l'eremita. A banda dels fets miraculosos propis d'aquest tipus de literatura, la Vita recull diversos aspectes que semblen versemblants. Primer, l'establiment de Ramon en una vall solitària i feréstega anomenada després Vallbona. Segon, que en algun moment fou molestat pels sarraïns de Siurana i que fou traslladat en aquest lloc; tercer, que va tenir alguns deixebles, com un jove i una dona anomenada València; quart, que va disposar d'alguns animals - dues vaques i un brau-; i cinquè, que fou visitat pel seu germà. De fet, els documents coetanis confirmen tots aquests aspectes, llevat de l'episodi relatiu a Siurana, que tampoc pot ser descartat taxativament, doncs petites inclusions sarraïnes al territori cristià fronterer degueren ser sovintejades per aquella època.

\footnotetext{
${ }^{27}$ Arxiu del monestir de Vallbona, Índex vell, f. 68r. Aquest document està datat per l'any 1153 de l'Encarnació, que correspon al 1154 de l'era comuna. Aquest detall ha estat oblidat pels historiadors del nostre cenobi que generalment han assignat la primera referència documental de l'eremitori de Vallbona a l'any 1153. Es evident, per tant, que cal retraçar en un any -el 1154 - el primer document vallbonenc.
} 
D'altra banda, la donació de 20 de juliol de 1157 d'un alou que Ramon de Cervera i Ponceta tenien a la vall de Vallbona i que afrontava pel nord amb el terme de Rocafort i pel migdia amb el dels Omells, esmenta l'"Alou de Santa Maria", com a la seva afrontació ponentina ${ }^{28}$. Això pressuposa, per consegüent, que com a mínim a l'estiu de 1157 existia ja una propietat aloera anomenada Santa Maria de Vallbona, que responia a ben segur a l'existència d'una esglesiola dedicada a la Mare de Déu, bastida probablement pels mateixos residents i tinguda com a església pròpia del centre eremític i atesa pel prevere Pere. De fet aquesta donació la rebien els frares que hi residien, és a dir, l'eremita Ramon, el capellà Pere i Ramon Duran.

A mitjan tardor d'aquest mateix any Pere d'Aguda, juntament amb els seus, donava als eremites -els tres anteriors- el lloc de Vallbona, que deuria correspondre a l'alou propi dels anacoretes ${ }^{29}$. És molt probable que aquesta donació sigui simplement una confirmació i en tot cas una cessió dels drets que aquest cavaller tenia o podia reclamar en el terme dels ermitans. És precisament en aquest instrument on es troben per primera vegada enregistrades les partions de Vallbona que - diu - confronten per solixent amb l'alou de Ramon de Cervera, pel migdia amb la Font d'Omells, per septentrió amb el terme de Rocafort i per ponent amb la Font de Llorenç o de Bell Llinar. Sembla, tanmateix, que per aquest temps el grup eremític es trobava ben constituï, ja que els seus membres reben el qualificatiu de "fratres" i que, d'altra banda, el seu nombre ultrapassava els tres esmentats ja que el document, fa referència també "als altres frares que serveixen a Déu en el lloc de Vallbona".

És molt probable que aquest moviment que es donà a la segona meitat de l'any 1157 a Vallbona fos motivat per la nova situació creada arran de la donació de Sòrboles a Ramon i els seus companys i que per aquesta raó Ramon de Vallbona posà cura a arranjar el grup vallboní per a poder-se dedicar, després, a la materialització del projecte comtal. Coincidint amb tots aquests fets, Ramon desapareix de la documentació vallbonina. Quan, però, tornem a tenir notícies d'ell el trobem al Montsant.

\footnotetext{
${ }^{28}$ Josep Joan PIQUer I JOVER, Cartulari de Vallbona (1157-1665), "Boletín de la Real Academia de Buenas Letras de Barcelona”, XXXVII (1977-1978), p. 75, doc. 2.

${ }^{29}$ Josep Joan PIQUeR I Jover, Cartulari de Vallbona (1157-1665), "Boletín de la Real Academia de Buenas Letras de Barcelona”, XXXVII (1977-1978), p. 76, doc. 3.
} 
Tot fa pensar, doncs, que el projecte de Sòrboles auspiciat per Ramon Berenguer IV no es dugué a terme i que ben aviat fou abandonat pels seus promotors. De fet era difícil que reeixís el pla del comte barceloní de fundar una abadia benedictina tan aprop de Poblet. La dotació territorial inicial del monestir cistercenc - les terres compreses en l'Hort de Pobletera molt superior a les sis parellades amb què havia de començar la seva singladura Sòrboles. Encara més, abans de la concessió d'aquest darrer lloc als ermitans, Poblet ja havia eixamplat enormement el seu patrimoni originari afavorit pel mateix comte -com la donació el 1155 del lloc de Doldellops, i a començament de l'any següent, la concessió de l'Hort de Bas, situat a Garcia- i també per nobles i benefactors, com els Cervera, Torroja, Alentorn, Rajadell i Sanaüja, que maldaren en protegir el nou monestir mitjançant concessions de terres, horts, vinyes i cases, principalment als territoris recentment conquerits de Tortosa i Lleida. Més emblemàtica fou, en tot cas, la donació del territori d'Avinganya, feta pel pròcer Guerau de Jorba o la somada de sal setmanal a percebre a Cardona concedida per Ramon de Cardona, juntament amb la comtessa Guillema.

La potència econòmica de Poblet — plasmada fins i tot en la solidesa de les primeres construccions del cenobi tot just iniciades- ofegà les pretensions benedictines, de manera que l'orgull del monestir de la Conca eclipsà la humilitat del no-nat cenobi de les Garrigues.

El fracàs de Sòrboles, però, no desencoratjà l'eremita Ramon en la seva tasca de promoció de l'eremitisme. Ramon continuà dirigint el grup vallboní que precisament per aquesta època deuria rebre diversos ingressos de confrares fet que determinà que s'anès consolidant com una comunitat eremítica mixta. Símptoma del procés assolit en fou el sorgiment, a partir del nucli inicial de Santa Maria, d'un altre de nou, el del Sant Esperit, situat a uns tres quilòmetres del primer ${ }^{30}$. No sabem si aquesta dualitat d'eremitoris respongué a la necessitat de separació de sexes o simplement al fet de l'increment del nombre d'eremites que aconsellà la creació d'un nou centre dins el mateix terme de Vallbona tot formant part del mateix grup, malgrat de residir els seus membres en llocs diferents, si bé no gaire distants.

\footnotetext{
${ }^{30}$ Sobre aquest lloc vegeu Josep-Joan PIQUER I JOVER, La baronia de Vallbona (Notes d'estudi), Lleida, 1981, pp. 39-41.
} 


\section{RAMON DE CERVERA, BENEFACTOR DE LA PRIMERA COMUNITAT EREMÍTICA DE VALLBONA}

La fama que assolí l'eremitori de Vallbona motivà que els senyors del seu entorn més immediat l'afavorissin amb concessions de noves propietats i drets. D'entre totes les concessions que obtingué per aquest temps destaca la de Ramon de Cervera, senyor eminent del sector de la Serra del Tallat, on precisament per assegurar les futures actuacions que a partir de 1150 havia d'iniciar amb el seu germà Ponç a l'Espluga de Francolí, organitzà una sèrie de castells en el territori més meridional i ponentí dels Comalats, tot donant-los a vassalls per tal que bastissin les corresponents torres $\mathrm{i}$ atraguessin gent que posés en conreu les terres adjacents ${ }^{31}$. Els castells de Belltall, el Tallat, Rocallaura, Montesquiu, els Omells de Na Gaia i Montblanquet formarien part del rosari castral bastit en el sector per Ramon de Cervera ${ }^{32}$.

Potser s'hauria d'atribuir a Ramon de Cervera la concessió del territori inicial de la futura comunitat eremítica de Vallbona. En efecte, aquest lloc estava situat al marge més nord-occidental dels seus dominis als Comalats, al límit amb els que hi posseïen els Cardona ${ }^{33}$. Després de l'actuació del comte Ramon Berenguer IV a Poblet i la posterior concessió de la població de Vimbodí als seus repobladors, els ermitans que vivien a l'indret de la Conca s'hagueren de desplaçar a un lloc més solitari. No resulta una hipòtesi inversemblant de suposar que per tal de solucionar la seva situació, fos Ramon de Cervera qui els hi oferís un altre emplaçament

\footnotetext{
${ }^{31}$ Josep Maria SANS I TRAVÉ, La carta de franquícia de Belltall (19 de novembre de 1227), "Universitas Tarraconensis", 1 (1976), pp. 48-51; Josep Maria SANS I TRAVÉ, Pere de Queralt, primer feudatari de l'Espluga de Francolí (1150-1166), "Universitas Tarraconensis", 2 (197778), pp. 26-36.

${ }^{32}$ Josep Maria SANS I TRAVÉ, La carta de població $i$ franquícia de Belltall (19 de novembre de 1227), "Universitas Tarraconensis", I (1976), p. 48.

${ }^{33}$ Sobre les activitats dels Cardona i la canònica de Sant Vicenç a Maldà, vegeu Andreu Galera I PEDRosa, Diplomatari de la vila de Cardona (anys 966-1276), Barcelona, Fundació Noguera, 1998, doc. 33, pp. 103-108, doc. 63, pp. 130-132, doc. 66, pp. 134-138, doc. 180 , p. 254 , doc. 184 , pp. $258-260$, doc. 185 , p. 260 , doc. 191 , pp. $267-270$, i doc. 195 , pp. $273-$ 276; vegeu també Montserrat CASAS I NADAL, La canònica de Sant Vicenç de Cardona a l'Edat Mitjana. Alguns aspectes de la seva història des dels seus orígens fins al 1311, a Història de Cardona, Ilibre III, $1^{\text {a }}$ part, Cardona, 1992.
} 
per a dur a terme la seva activitat eremítica i que fos precisament al límit dels seus propis dominis, que en aquell moment deuria ser un lloc per repoblar i que pel seu apartament i solitud era ben adequat per als ermitans.

Aquest pròcer tot i que havia palesat la seva simpatia pel monestir de Poblet en el moment en que el comte cedí a l'abat de Fontfreda l'Hort de Poblet el 18 de gener de 1150 donant al futur monestir la meitat de l'Hort de Sant Salvador perquè integrés el terme del futur cenobi, sembla que en els anys immediatament posteriors a la implantació de la comunitat cistercenca les relacions amb aquesta no foren especialment fluïdes si ens atenem que fins al 3 de maig de 1166 la documentació no registra cap donació al monestir veí, el qual, d'altra banda, fou escollit com a lloc del seu enterrament, segons testament atorgat el 19 d'octubre de $1172^{34}$. Per contra, Ramon de Cervera per aquests anys afavorirà els grups eremítics de Vallbona i del Sant Esperit als quals donà el 18 de juliol de 1164 el castell de Colobres, i, a més, l'església de Sant Joan, amb la dotació d'una parada d'alou, les primícies, oblacions i preveres ${ }^{35}$. Bona part dels historiadors del nostre monestir, així com la mateixa tradició monàstica han identificat aquest castell amb el de Montesquiu basant-se en un document de 15 de març de 1220, on s'afirma que Dolça de Passanant en oferir-se ella mateixa com a conversa del monestir li concedí els béns que posseïa "in castro Colobrario qui vocatur Montiesquivi" ${ }^{36}$. D'altres, però, l'han identificat amb el del Tallat en base d'un document de 1305 , recollit pel P. Pasqual ${ }^{37}$, en què en una venda d'una dominictaura amb la fortificació que hi havia bastida es diu que "estava situada en el lloc anomenat lo puig de Tallat que en altre temps

\footnotetext{
${ }^{34}$ Agustí Altisent, Diplomatari de Santa Maria de Poblet. Volum I. Anys 960-1177, Generalitat de Catalunya, Barcelona, 1993, doc. 441, pp. 330-331.

${ }^{35}$ Joan Josep PIQUER I JOVER, Cartulari de Vallbona (1157-1665), "Boletín de la Real Academia de Buenas Letras de Barcelona", XXXVII (1977-1978), doc. 4, pp. 76-77.

${ }^{36} \mathrm{P}$. Jaime PASQUAL, Llibre vert, p. 77. Aquesta informació la recull també Joan Josep PIQUER I JOVER, Abaciologi de Vallbona (1153-1977), Santes Creus, 1978, p. 73, on data erròniament el document el 15 de maig de 1219, i el mateix Joan Josep PIQUER I JOVER, Cartulari de Vallbona (1157-1665), "Boletín de la Real Academia de Buenas Letras de Barcelona”, XXXVII (1977-1978), doc. 23, p. 92, on es data l'any 1219, quan els idus de març corresponen al 1220 de l'any comú. Una referència que pot ser aclaridora respecte al castell de Colobres hom la pot trobar a l'instrument de venda d'unes propietats situades a Senan que el 5 de juliol de 1170 féu Guerau de Granyena al monestir de Montserrat (Vegeu Agustí Altisent, Diplomatari de Poblet. Volum I. Anys 960-1177, Generalitat de Catalunya, Barcelona, 1993, doc. 378, p. 287.

${ }^{37}$ P. Jaime PASQual, Carta al Marqué de Capmany, obra cit. núm. 2, p. 6
} 
s'anomenaca lo Puig Colobres" ${ }^{38}$. En un altre lloc ja hem demostrat que no hi ha cap relació entre el castell del Tallat i Colobres ${ }^{39}$.

La concessió del castell de Colobres tingué un significat molt important per a la futura comunitat vallbonina, atès que el lloc fou ocupat pels eremites, de manera que a final de la dècada dels anys seixanta del segle XII el nucli eremític de Vallbona estava integrat per tres centres: l'inicial de Santa Maria, el del Sant Esperit i el de Colobres. Cada un d'ells disposava d'una església o capella per atendre les necessitats dels seus membres i que eren les de Santa Maria, Santa Llúcia i Sant Joan, respectivament.

D'altres feudals de la contrada amb drets a tocar a Vallbona palesaren també per aquesta època la seva devoció per la comunitat d'anacoretes. És el cas, per exemple, de Pere d'Aguda - un vassall dels Cardona afincat en aquest sector- qui el juny de 1169 donava al grup vallboní l'alou anomenat de Sant Llorenç, que tocava al terme del mones$\operatorname{tir}^{40}$.

\section{L'ORGANITZACIÓ DE NOUS CENTRES EREMÍTICS PER PART DE RAMON DE VALLBONA}

Mentre tot això succeïa a Vallbona, l'eremita Ramon, fracassat l'intent de Sòrboles, estava ocupat en l'organització de nous centres d'anacoretes més al sud. La seva personalitat com a promotor de l'eremitisme havia arribat fins i tot a la cort reial i havia aconseguit interessar la mateixa persona del monarca. En efecte, Alfons I manà al seu castlà de Siurana Arbert de Castellvell que concedís un lloc al Montsant a l'esmentat Ramon de Vallbona on pogués fundar un nou eremitori de manera que esdevingués un element més de la consolidació del repoblament a la contrada. Arbert complia el mandat reial el 12 de setembre de 1164 i donava a Ramon, al sacerdot Pere $\mathrm{i}$ als altres confrares que vinguessin amb ell el lloc que després havia de ser Poboleda, amb la facultat de poder bastir un 31.

${ }^{38}$ Josep Joan PIQUER I JOVER, Abaciologi de Vallbona (1153-1977), Santes Creus, 1979, p.

${ }^{39}$ Josep Maria SANS I TRAVÉ, Història del Tallat, Lleida, 1986, pp. 51-53.

${ }^{40}$ Josep Joan PIQUER I JOVER, Cartulari de Vallbona (1157-1665), “Boletín de la Real Academia de Buenas Letras de Barcelona”, XXXVII (1977-1978) doc. 5, pp. 77-78. 
molí que aprofités les aigües del riu Montsant ${ }^{41}$. És probable que vers 1171 ja s'hagués constituït una comunitat eremítica ja que un document d'aquest any donat a conèixer per Josep Trenchs posa com a afrontació d'una terra de la vall de Porrera "la població dels monjos de Poboleda" 42.

Durant un temps les activitats de Ramon de Vallbona es cenyiren a la direcció d'aquest nou centre eremític del Montsant; per bé que com a pare espiritual i responsable del nucli de Vallbona no degué ser aliè als esdeveniments que aquí s'estaven produint.

$\mathrm{Al}$ respecte, crec que puc avançar com a hipòtesi la possibilitat que el centre de Poboleda tingués una certa vinculació jurídica amb el grup de Vallbona. Dic això perquè quan el 5 d'octubre de 1173 Gombau de Talarn professava com a religiós eremita a Santa Maria de Poboleda, tot prometent fidelitat, castedat i obediència, ho feia davant de Ramon de Vallbona que l'acollia en la comunitat ${ }^{43}$. Pel fet que el profès concedia a Poboleda dues sorts de terra que posseïa al terme de Verdú, a més d'altres béns, el document era signat pel vell senyor d'aquest lloc, Berenguer Arnau d'Anglesola, el seu fill Guillem i Berenguera d'Anglesola o Cervera, qui rebé Verdú juntament amb el seu marit el 18 d'abril de $1164^{44}$. Aquesta dona, que feia poc temps que havia restat vídua de Guillem de Cervera -aquest noble degué morir a final d'octubre de $1172^{45}$-, almenys a partir d'aquest moment, el mes d'octubre de 1173, estigué en contacte amb Ramon de Vallbona.

\footnotetext{
${ }^{41}$ Agustí Altisent, Diplomatari de Santa Maria de Poblet. Volum I. Anys 960-1177, Generalitat de Catalunya, Barcelona 1993, doc. 264, p. 209.

${ }^{42}$ Citat per Agustí Altisent, Ramon de Vallbona i l'eremitori de Poboleda, "Studia Monastica”, 10 (1968), p. 144.

${ }^{43}$ Agustí Altisent, Diplomatari de Santa Maria de Poblet. Volum I. Anys 960-1177, Generalitat de Catalunya, Barcelona, 1993, doc. 470, p. 352.

${ }^{44}$ Ibidem, doc. 258, p. 205.

${ }^{45}$ Berenguera de Cervera signava com a testimoni el 31 d'octubre de 1172 de la donació d'una terra a Barbens feta pel seu germà Guillem d'Anglesola al monestir de Poblet, on feia constar que "va ser muller de Guillem de Cervera". El 26 d'abril de l'any següent, -per tant encara no s'haurien acomplert els sis mesos preceptius des del traspàs del seu marit per tal de dur a terme la declaració del testament- Berenguera juntament amb Berenguer de Boixadors, Arnau de Timor i el notari Iteri juraven sobre l'altar de Santa Maria de Gardeny les darreres voluntats de l'esmentat Guillem de Cervera. (Vegeu Agustí AlTiSENT, Diplomatari de Santa Maria de Poblet. Volum I. Anys 960-1177, Generalitat de Catalunya, Barcelona, 1993, doc. 443, pp. 332-333 i doc. 457, pp. 341-342). Per consegüent cal rectificar la data de la mort de Guillem III que G. Gonzalvo i M. Salas atribueixen a l'any 1173 [Gener GoNZALvo-Manel SALAS, Guillem de Cervera, cavaller i monjo de Poblet, "Anuario de Estudios Medievales", 28 (1998), p. 414, nota 55]
} 
D'altra banda, quan aquest mateix Gombau, el 17 d'octubre de 1176 venia una peça d'alou en el terme de Verdú, assenyalava que realitzava la venta "amb consell i voluntat de l'abadessa de Santa Maria de Vallbona"46. Sembla, per tant, que en aquest darrer cas l'actuació de Gombau estava recolzada per l'abadessa i que mantenia, per tant, una vinculació jurídica, traspassat Ramon, amb la seva successora legal, l'abadessa.

\section{L'Alienació de Sòrboles a Poblet \\ (1 D'ABRIL DE 1171)}

Les actuacions al Montsant no van impedir que Ramon de Vallbona continués mantenint el seu interès per Sòrboles, tot i que Poblet havia intentat neutralitzar qualsevol possible futura actuació dels eremites en aquest indret.

Amb aquest objectiu el monestir de la Conca s'havia introduït en el domini del lloc. Primer, el mes de juny de 1161 havia obtingut les terres conreades i ermes que hi tenia Berenguer Campairol ${ }^{47}$. Però, seria al cap de dos anys, el 29 de desembre de 1163, quan Poblet aconseguiria el domini feudal de Sòrboles gràcies a la concessió de Guillem de Cervera i la seva dona Ermesen amb motiu de lliurar-se com a donats i escollir el monestir per a destí final de les seves despulles ${ }^{48}$. A més, els concedents cedien al cenobi, en mans de l'abat Esteve, quinze parellades de terra al lloc on volguessin de l'esmentat territori com a propietat i la facultat de bastir-hi molins. Per garantir més la concessió, el rei Alfons signava l'instrument.

Aquesta disposició tallava dràsticament les possibles actuacions de Ramon de Vallbona a Sòrboles, ja que no podia expansionar-se més enllà de les sis parellades amb què els havia dotat Ramon Berenguer IV. Poblet, conscient de la importància d'evitar qualsevol expansió dels eremites en aquest lloc, $s$ 'hi afincà tot seguit constituint una granja amb les propietats que hi havia rebut, de manera que quan el 1172, aconseguí d'Alexandre III

${ }^{46}$ F. Solsona, Pergamins de Vallbona de les Monges a l'A.H.N. de Madrid, a "Primer Col.loqui d'Història del Monaquisme Català", Santes Creus, 1967, I, p. 327.

${ }^{47}$ Agustí Altisent, Diplomatari de Santa Maria de Poblet. Volum I. Anys 960-1177, Generalitat de Catalunya, Barcelona, 1993, doc. 221, p. 182.

${ }^{48}$ Agustí Altisent, Diplomatari de Santa Maria de Poblet. Volum I. Anys 960-1177, Generalitat de Catalunya, Barcelona, 1993, doc. 251, pp. 200-201. 
una butlla de protecció per al monestir i les seves possessions i béns, es feia esment específic de la ja "granja de Sòrboles", fet que confirmaria l'existència d'aquesta explotació a la dita data ${ }^{49}$.

D'altra banda, sembla que els tres beneficiaris inicials de Sòrboles de fet no varen establir-se aquí o bé no varen crear cap mínima infrastructura o construcció, com podia haver estat una petita esglesiola - seguint la tradició de Vallbona - per a l'atenció de les seves necessitats de culte, tal com confirmarà el que direm més endavant.

Després que Poblet obtingués de Guillem de Cervera el terme de Sòrboles, Ramon de Vallbona va desistir definitivament de tirar endavant el vell projecte de la fundació d'una abadia planejat per Ramon Berenguer IV. Com que naturalment no valia la pena enfrontar-se amb la potència del monestir de la Conca que, a més, en la seva expansió a Sòrboles comptava amb el suport d'Alfons I, Ramon optà per arribar a un acord abans que entrar en una guerra per l'hegemonia del lloc que, en cas d'iniciar-se, tenia probablement ben perduda. El primer d'abril de 1171 l'esmentat anacoreta atorgava el seu consentiment al contingut dels pactes establerts amb l'abat Hug de Poblet ${ }^{50}$. La redacció d'aquest document feta pel monjo del cenobi Esteve es degué realitzar en el mateix monestir de Poblet a on es desplaçaren l'eremita Ramon, el seu germà Poculull i el seu deixeble Bernat, essent-hi també presents els monjos Esteve, prior del monestir, Pere de Queralt, cellerer major, i Bernat de Portarrègia, així com cavallers $\mathrm{i}$ homes de l'entorn relacionats amb el cenobi com ara Pere de Malacara, Pere Bord, Elies i el seu cunyat Donat.

Ramon, doncs, en lloc d'enfrontar-se amb els cistercencs, preferí entrar en la germandat espiritual del monestir, una solució que per aquests anys havia utilitzat el cenobi -i que continuà encara utilitzant sovint- en els casos de persones i famílies amb les quals havia topat, sobre tot arran de conflictes patrimonials. És evident, d'altra banda, que l'ingrés en la germandat era també el pagament de deixes o llegats als benefactors. En el cas de Ramon es procedí de la mateixa manera, doncs, que s'actuaria més endavant, per exemple, amb els terratinents espluguins del Codós, que implicà generalment que renunciessin a les seves propietats en favor del

\footnotetext{
${ }^{49}$ Agustí Altisent, Diplomatari de Santa Maria de Poblet. Volum I. Anys 960-1177, Generalitat de Catalunya, Barcelona, 1993, doc. 426, pàgs. 320-321.

${ }^{50}$ Agusti Altisent, Diplomatari de Santa Maria de Poblet. Volum I. Anys 960-1177, Generalitat de Catalunya, Barcelona, 1993, doc. 399, p. 300.
} 
monestir per bé que aquest després els concedí en general la tinença de per vida $^{51}$.

Ramon, però, donada la seva condició eremítica, negocià alguns aspectes que li fossin especialment beneficiosos. A més, en aquells moments, es trobava amb ell un deixeble anomenat Bernat, que seguia els seus ensenyaments i el mateix model de vida eremítica. Ramon aconseguí en compensació, una mena de vitalici en natura per a ell i el seu deixeble que comportà menjar i vestits de per vida, concretats en 12 mitgeres de farina de forment per a dues persones, i quant al vestit, per a Bernat, una cogulla cada any, mentre que per a Ramon els tres elements típics dels monjos cistercencs: una túnica, una cogulla $i$ un escapulari; $i$, a més, dos parells de sandàlies, un capell rodó $\mathrm{i}$ un càntir d'oli - a mesura de Tortosa - en entrar al temps de Quaresma.

Finalment, Ramon obtenia també que Poblet li bastís un petit habitacle d'anacoreta, consistent en un oratori - del qual se'n fixaven les característiques, cinc braces de llargària per dues d'amplada, fet a base de pedra i calç, amb coberta de teules o maons - i una petita cel la al seu costat on ell pogués retirar-se sol a fer oració.

Tot això, però, el beneficiari ho tindria només de per vida i també del seu deixeble si li sobrevisqués, passant després de la mort de tots dos al monestir.

La historiografia tradicional ha assignat Vallbona com el lloc on Poblet es va comprometre a bastir aquesta edificació. L'eminent historiador del monestir, Josep Joan Piquer i Jover afirma al respecte: "podem garantir que la capella fou bastida sobre la roca de Santa Maria i la cel·la va ser excavada dessota, a sis metres de profunditat de la planta del temple"52. Crec. però, que és molt més lògic suposar que la construcció es fes a Sòrboles mateix, on Poblet ja disposava del domini feudal del lloc i també d'una part de les terres del terme. Al cap i a la fi d'aquesta manera, els cistercencs construïen en un lloc que els havia de pervenir i situat dins els seus dominis. I de fet, traspassat Ramon, els monjos es preocuparen d'obtenir les renúncies dels que podien al·legar drets en l'eremitori. Primer, el mes de setembre de 1179, Ramon de Potellas, fill de Poculull, el germà

\footnotetext{
"Agustí ALTISENT, Un poble de la Catalunya Nova els segles XI i XII. L'Espluga de Francolí de 1079 a 1200. “Anuario de Estudios Medievales”, 3 (1966), pp. 170, 178-179 i 189. p. 33,

52 Josep Joan PIQUER I JOVER, Abaciologi de Vallbona (1153-1977), Santes Creus, 1978,
} 
de Ramon de Vallbona, i per tant, nebot d'aquest, cedia tots els drets que pogués tenir a la Coma Fumada, la partida de Sòrboles que havia pertangut als anacoretes, i confirmava la donació feta pel seu oncle, amb l'acord també del seu pare. Poblet pagava aquesta renúncia amb 43 sous barcelonesos ${ }^{53}$.

A aquesta renúncia familiar, al cap d'uns anys, el 13 d'abril de 1213, Poblet aconseguí també la del monestir de Vallbona, que d'alguna manera, havia estat l'hereu jurídic de l'eremita ${ }^{54}$.

\section{LA INCORPORACIÓ DE VALlbona A L'ORDE DEL Cister} (1171)

A començament de la dècada del setanta del segle XII s'esdevingué un fet que havia de suposar un canvi radical en les comunitats eremítiques de Vallbona i que havia de tenir una transcendència determinant en el seu futur. Em refereixo naturalment a la incorporació a Citeaux d'aquest grup d'anacoretes.

Una notícia procedent dels arxius de Citeaux, enregistrada actualment en un manuscrit de la Biblioteca Nacional de París, ens informa que el setembre de 1171 el Capítol General del Cister aprovà la integració de Vallbona a l'orde. Aquesta data s'aproxima a l'any 1173, que segons la tradició del monestir, des de les èpoques més remotes, assenyala com el de la seva fundació.

Aquest esdeveniment, però, no el tenim confirmat documentalment en les fonts arxivístiques originals de Vallbona, ja que no hem trobat cap pergamí que recollís aquesta disposició, per bé que cal pensar que el Capítol General de Citeaux degué fer una comunicació escrita de la decisió adoptada.

Les circumstàncies que determinaren la petició de l'ingrés a l'orde del Cister tampoc són ben conegudes, tot i que la historiografia tradicional, no contrastada per documents coetanis, representada pel P. Pasqual assenyala que Berenguera de Cervera, que probablement a partir de 1157 estava ja retirada a Vallbona o potser s'hi desitjava retirar ${ }^{55}$, aconseguí després de

\footnotetext{
${ }^{53}$ Cartulari de Poblet, Barcelona, Institut d'Estudis Catalans, 1938, doc. 148, p. 86.

${ }^{54}$ Josep Joan PIQUER I JOVER, Cartulari de Vallbona (1157-1665), "Boletín de la Real Academia de Buenas Letras de Barcelona”. XXXVII (1977-1978), doc. 22, pp. 91-92.

${ }^{55}$ Jaime PASQual, Carta al Marqués de Capmany, p. 8, núm. 7.
} 
la mort de Ramon de Vallbona, la incorporació del grup cenobític a Citeaux $^{56}$, i, a més, sabé convèncer Òria perquè abandonés l'abadia de Colobres $\mathrm{i}$ es traslladés a presidir la comunitat de Vallbona ${ }^{57}$. L'erudit premostratenc basa aquestes afirmacions en el text que recull l'antic abaciologi del monestir: "Prima nobilis domina que fuit in monasterio Vallisbone fuit domina Berengaria de Cervera, que fecit incorporare monasterium in ordinem et ivit apud Colobres et adduxit secum dominam Oriam, que fuit prima abbatissa Vallisbone".

L'eminent historidaor de Vallbona, Josep Joan Piquer i Jover segueix pràcticament la mateixa opinió que el $\mathrm{P}$. Pasqual en afirmar que Berenguera de Cervera, després de restar vídua de Guillem III de Cervera, senyor de Juneda, es posà al front del monestir, malgrat que no fos monja, i emprengué les negociacions per fer incorporar el cenobi a l'orde del Cister el $1176^{58}$. També, segons aquest autor, fou aquesta senyora la que es traslladà al monestir navarrès de Tulebras d'on portà Òria, destinada a governar l'abadia de Vallbona. Piquer basa també la seva opinió en el text del vell abacilogi vallboní, tot i que rectifica el lloc de Colobres pel de Tulebras, el cenobi d'on vingueren les monges cistercenques per ensinistrar la nova comunitat $^{59}$. Aquest autor afegeix, finalment, que fou degut als fins dots diplomàtics de Berenguera que s'obtingué la no dependència de la casa-mare, fet que no passà amb les restants fundacions de Tulebras.

Aquestes afirmacions s'han de matissar i en alguns aspectes, fins $\mathrm{i}$ tot rectificar. En primer lloc, perquè hi ha diversos anacronismes que no lliguen; segonament, perquè tot i acceptant la importància de Berenguera en la decisió d'incorporar Vallbona al Cister, no es pot pretenir el paper de Ramon; i en tercer lloc, perquè quan es redactà el text de l'abaciologi fou el 1225 , amb motiu precisament del traspàs d'aquesta senyora, quan havien ja passat setanta-dos anys dels principals esdeveniments. No es pot oblidar, d'altra banda, el contingut encomiàstic de l'inici d'aquest abaciologi.

D'altra banda, si Berenguera de Cervera hagués tingut la responsabilitat directa d'incorporar la comunitat d'anacoretes a Citeaux, no hi ha dubte

\footnotetext{
${ }^{56}$ Jaime PASQual, Carta al Marqués de Campmany, p. 15, núm. 18.

${ }^{57}$ Jaime PASQUAL, Carta al Marqués de Campmany, pp. 15-16, núm. 19.

${ }^{58}$ Josep Joan PIQUER I JOVER, Abaciologi de Vallbona (1153-1977), Fundació Roger de Belfort, Santes Creus, 1978, pp. 38-39.

59Josep Joan PIQUER I JOVER, Abaciologi de Vallbona (1153-1977), Fundació Roger de Belfort, Santes Creus, 1978, p. 39.
} 
que aquesta circumstància s'hauria ressenyat en la resolució que adoptà el capítol general el 8 d'abril de 1225 concedint a la comunitat vallbonenca la celebració d'un aniversari el dia que es commemorava la seva mort. Els mèrits al-legats se cenyiren als "honors $\mathrm{i}$ molts beneficis que la senyora Berenguera de Cervera, mare de Guillem de Cervera i d'Aldiarda d'Àger" -els dos en aquells moments cistercencs- "ha concedit al monestir de Santa Maria de Vallbona"60.

Els fets deurien ser, a criteri meu, un xic diferents. Quan el 1171 Ramon de Vallbona arribà a un acord amb Poblet al qual cedí després de la seva mort la propietat de Sòrboles, $\mathrm{i}$ ingressà en la germandat espiritual del Cister, ell mateix esdevingué, tot i mantenint la seva condició d'anacoreta, en certa manera un cistercenc i així volgué aparèixer públicament atès que el monestir es comprometé a donar-li els hàbits propis d'aquests tipus de monjos.

A ben segur que la seva relació amb els cistercencs li aportà la idea que una solució per al futur de la comunitat eremítica femenina de Vallbona podia ser la seva vinculació amb el Cister que per aquells anys ja havia fundat al regne de Navarra un monestir de dones a Tulebras (1157). Amb aquest propòsit, doncs, Ramon es dirigí al Capítol General de Citeaux perquè aprovés la incorporació de la petita comunitat que com a responsable i pare espiritual dirigia. Sembla versemblant que la petició de Ramon fos cursada precisament a través de l'abat de Poblet qui, per raó del seu càrrec, estava en contacte - almenys una vegada a l'any, amb motiu de la celebració del capítol general- amb Citeaux. I també sembla versemblant de pensar que fou l'abat de Poblet Hug, qui havia rebut l'anacoreta en la germandat cistercenca, la persona que presentà i defensà davant els altres abats la sol-licitud de Ramon i la idoneïtat de la seva concessió.

Per tant, després de l'acord que Ramon suscrigué amb el monestir de Poblet, l'anacoreta féu cursar la petició al Capítol General de Citeaux, el qual l'aprovà el mes de setembre del mateix any.

${ }^{60} J o s e p$ Joan PIQUER I JOVER, Cartulari de Vallbona (1157-1665), "Boletín de la Real Academia de Buenas Letras de Barcelona”, XXXVII (1977-78), doc. 24, p. 93. 


\section{LA DISTRIBUCIÓ DELS EREMITES VALLBONENCS \\ I LA SOL·LICITUD DE MONGES CISTERCENQUES \\ A TULEBRAS (NAVARRA)}

Arran d'aquesta circumstància l'eremita hagué de solucionar el problema que presentava, d'una banda, l'existència a Vallbona d'una comunitat mixta, integrada per homes i dones que probablement habitaven en els distints llocs de la contrada eremítica; i, de l'altra, la manca de tradició cenobítica cistercenca femenina que pogués guiar aquelles anacoretes cap a una forma de vida de pobresa evangèlica i més en comú, d'acord amb els nous valors religiosos que propugnava la reforma del Cister.

Quant al primer aspecte, Ramon intentà dirigir cap a Poboleda els homes que volien seguir la vida eremítica i que anaven a trucar a la seva porta. Un bon exemple el podria representar Gombau de Talarn, un personatge oriünd de Verdú, qui en professar com a eremita el 5 d'octubre de 1173 davant de Ramon de Vallbona expressava la seva voluntat de fer-ho a Santa Maria de Poboleda ${ }^{61}$. És probable, però, que els anacoretes afincats ja a Vallbona -que deurien ocupar el lloc del Sant Esperit-optessin per romandre aquí i no traslladar-se al Montsant. Per consegüent només deurien ser dirigites cap a Poboleda les noves vocacions eremítiques mentre que els ermitans que ja havien començat la seva vida a l'entorn de Vallbona degueren romandre aquí. La seva existència sovint és confirmada per la documentació, com són els casos de fra Ponç i Bernat de Navaes que el 17 d'octubre de 1176 consten com a membres del convent de Vallbona ${ }^{62}$, tot i que aquest darrer estava també present a l'acte de professió de l'esmentat Gombau de Talarn.

L'aspecte relatiu a la formació espiritual de les noves monges Ramon l'arranjà demanant al monestir de Tulebras que li enviessin algunes religioses per tal que ensinistressin les neòfites cistercenques en la vida cenobítica que propugnava l'orde. La tradició, no contrastada documentalment, del monestir vallbonenc, que recull el P. Caresmar, exposa que de la comunitat navarresa vingué l'octubre de 1172 a Vallbona Òria, acompanyada de dues monges i

\footnotetext{
${ }^{61}$ Agustí Altisent, Diplomatari de Santa Maria de Poblet. Volum I. Anys 960-1177, Generalitat de Catalunya, Barcelona, 1993, doc. 470, pàg. 352.

${ }^{62}$ Archivo Histórico Nacional, Madrid, Clero, Carpeta 1201, perg. núm 1.
} 
dues donzelles per tal d'implantar l'institut cistercenc ${ }^{63}$. Potser en això intervingué personalment Berenguera de Cervera, o simplement recolzà des de fora i donà suport a les actuacions de Ramon. En efecte, l'abaciologi del monestir assenyala que "fou aquesta senyora la primera dona noble que ingressà en el cenobi i qui va fer incorporar el monestir a l'orde”. No és descartable en aquest moment aquest tipus de gestió per part de Berenguera que podia haver realitzat davant l'abat de Poblet, amb qui per aquesta època mantenia tant ella com el seu marit bones relacions, derivades d'haver estat ja benefactors del cenobi masculí. En tot cas, però, crec que la iniciativa la dugué a terme personalment el responsable del grup, Ramon de Vallbona, atès que a ell com a promotor i director del centre li competia aquesta comesa. Potser, simplement, Berenguera des de la seva posició preeminent en el segle féu gestions per tal que Ramon aconseguís el seu propòsit.

Esdevinguts els fets d'aquesta manera que nosaltres proposem, Tulebras no hauria estat la casa-mare de Vallbona, atès que quan vingueren les monges navarreses les vallbonines ja haurien professat a l'orde del Cister, cenyint-se simplement la tasca de les primeres a ensinistrar els membres de la comunitat catalana en aquelles pràctiques i costums pròpies de l'orde, però en cap cas les monges estrangeres arribaren a Vallbona amb la voluntat de fundar un nou monestir ja que aquest ja existia. D'aquí que Vallbona no s'hagi considerat legalment mai una fundació de Tulebras, sinó una abadia directament depenent del Capítol General de Citeaux.

Coincidint amb les profundes transformacions que s'estaven efectuant a Vallbona, l'elevació als altars el 18 de gener de 1174 de Bernat de Claresvalls representà un element de propaganda dels cistercencs que veieren com molts fidels, desitjosos d'una major perfecció, demanaven per enrolar-se a les seves files o bé els feien objecte de les seves donacions pietoses. Vallbona no fou aliè, com a monestir cistercenc, a aquest moviment de generositat dels nobles, cavallers i pagesos del seu entorn.

El pas de la vida eremítica a la cenobítica determinà també un canvi substancial no només en aquells aspectes que pertocaven la vida interna de la comunitat sinó també en les seves bases econòmiques. La nova situació implicava, d'entrada, el poder disposar dels recursos econòmics suficients per poder fer front a les enormes necessitats que tenia una comunitat

$$
46 .
$$

\footnotetext{
${ }^{63}$ Josep Joan PIQUER I Jover, Abaciologi de Vallboria (1153-1977), Santes Creus, 1978, p.
} 
cenobítica, molt més gran en nombre de membres que un reduït grup d'anacoretes. Per atendre les exigències de menjar i vestit, ni que fossin emmarcades dins l'austeritat que propugnava Citeaux, calien força diners, així com també en calien per poder bastir les noves construccions monacals que s'havien de fer d'acord amb els principis arquitectònics i models monàstics que amb més o menys adequació seguien tots els centres cistercencs. Per això, no n'hi havia prou amb l'explotació de les terres que integraven l'antic terme de Santa Maria de Vallbona, sinó que era necessari cercar més recursos a través de l'adquisició i explotació de noves propietats per tal d'obtenir més rendes.

Ramon dirigí també la transformació inicial, com a responsable de la nova comunitat, de les bases econòmiques de Vallbona. El fundador propicià l'ingrés de noies nobles de la comarca que generalment aportaven una quantitat important de diners que s'invertien en cobrir aquelles necessitats que hem referit o bé en la compra de propietats. Així mateix, Ramon, amb un bon sentit econòmic de les inversions, adquirí terres i feus del costat de Vallbona per tal de treure'n els recursos adients que poguessin mantenir la futura comunitat. En aquest sentit, per exemple, el 25 d'agost de 1174 , comprava per 500 sous barcelonesos, a Berenguer de Cardona la dominicatura que aquest tenia al $V_{i l e t^{64}}$. Aquest acte té per al moment històric del cenobi una importància especial perquè, en primer lloc palesa que el grup cenobític disposava ja d'una certa economia monetària car pogué desembossar cinc cents sous per a adquirir el patrimoni del Vilet, i en segon lloc, que tenia ja un cert prestigi davant la societat catalana de l'època, atès que entre d'altres nobles i cavallers, es trobaven presents a l'acte el comte Ermengol VII d'Urgell i el bisbe Pere de Vic.

Progressivament també el nucli vallbonenc s'anà consolidant com un centre cenobític femení, per bé que aquesta especialització es degué dur a terme de forma gradual. Els documents que resten d'aquella època esmenten sovint a "Ramon i les monges que habiten a Santa Maria de Vallbona", o bé utilitzen el terme molt més precís de "domus", en el sentit de casa o convent.

Aquest canvi fonamental i la nova direcció que prenia el cenobi vallbonenc no passaren desapercebuts per la corona que ben aviat palesà la

\footnotetext{
${ }^{64}$ Josep Joan PIQuer I Jover, Cartulari de Vallbona (1157-1665), "Boletín de la Real Academia de Buenas Letras de Barcelona”, XXXVII (1977-1978), doc. 6, p. 78.
} 
seva simpatia pel nou grup cenobític que s'estava constituint, certament amb dificultats, al redòs de la Serra del Tallat, $i$ on ja algunes joves i dames procedents de la noblesa l'havien escollit com a centre per dur a terme una vida més evangèlica, retirades del món i consagrades a Déu.

Dins d'aquest context s'ha d'entendre la donació que el mes d'octubre de 1174 féu el rei Alfons I de la plaça de Boacar, a Lleida, al monestir de Vallbona i a Beatriu, que en aquest moment, probablement per absència temporal de Ramon de Vallbona, estava al front de la comunitat ${ }^{65}$. La presència de pròcers destacats del país, com ara els germans Guillem de Cervera - sogre de Berenguera, ja vídua de Guillem de Cervera el Jove $(\dagger 1172)-$ i Guerau de Jorba, i el fill d'aquest darrer Guillem d'Alcarras, palesa que l'acte tingué un especial relleu.

D'altra banda, aquesta concessió reial a Vallbona prova que efectivament en aquest indret hi havia constituida una comunitat religiosa -el document esmenta específicament el mot de domus o casa religiosa-, dirigida per una responsable, Beatriu, que deuria ser simplement una priora, atès que l'abadessa canònicament constituïda deuria residir a Colobres.

\section{El TESTAMENT DE RAMON DE VALLBONA}

(8 D'ABRIL DE 1176)

I LES SEVES CONSEQÜĖNCIES

Com hem assenyalat, en el sector nord-occidental de la Serra del Tallat s'hi varen constituir en el tercer terç del segle XII, promoguts per l'eremita Ramon de Vallbona, tres centres eremítics - un a la vall de Santa Maria, un altre al Sant Esperit i un tercer a Colobres- coneguts amb l'específic que els englobava tots tres, de Vallbona.

En tenia la direcció Ramon, que com a fundador i aglutinador actuava de guia espiritual i representant legal davant la societat. En conseqüència ell acceptava aquelles persones que abandonant la vida del segle es volien dedicar a l'oració i la penitència. Més encara, l'eremita actuava amb els centres que havia fundat, tant a Vallbona com a Sòrboles $\mathrm{i}$ a Poboleda, com si es tractés en certa manera de béns patrimonials: ell rebia

\footnotetext{
${ }^{65}$ Josep Joan PIQUER I JOVER, Cartulari de Vallbona (1157-1665), "Boletín de la Real Academia de Buenas Letras de Barcelona”, XXXVII (1977-1978), doc. 7, pp. 78-79.
} 
les donacions de nobles i particulars i també ell, en nom de les seves comunitats, adquiria els béns que havien d'engrossir el seu incipient patrimoni territorial.

Quan per raó de l'atenció als seus diversos centres, Ramon s'havia d'absentar, deixava sempre algú que es responsabilitzés de la direcció del corresponent grup. Malgrat els viatges sovintejats als centres per ell fundats, el seu lloc de residència habitual era Vallbona, on havia començat la seva vida d'anacoreta.

És molt probable que les monges de Tulebras que vingueren al sector de Vallbona per ensinistrar les ermitanes en la vida cenobítica, fossin establertes a Colobres, possiblement perquè aquest centre era més petit $\mathrm{i}$ molt més fàcil d'aglutinar els seus membres en el nou model de vida religiosa que propugnava Citeaux. Mentre que a Santa Maria romandria la resta de la comunitat, constituïda fonamentalment per aquells membres més reticents als canvis que implicava la nova vida cenobítica.

Coincidint amb aquests moviments tan transcendentals per al futur de Vallbona, es donà un fet que hauria de marcar el seu destí: la mort del fundador i prèviament l'atorgament del seu testament que solucionava definitivament la sort dels diversos grups femenins.

Ramon ja deuria ser vell i en tot cas un home decrèpit a causa dels viatges, l'alimentació a base de glans i herbes, els dejunis, les vigílies i la penitència. El seu cos trit per tantes inclemències ja no resistí més i la seva persona es preparà per retre al darrer dèbit mortal.

El dia abans del seu traspàs, el 8 d'abril de 1176 , en presència dels seus íntims, el seu germà Poculull, Guerau de Maldà, el sotsdiaca Reinald de Tarroja i de Pere, capellà de Loro, expressava les seves darreres voluntats l'anacoreta que s'encarregava de redactar l'esmentat capellà Pere $^{66}$.

Les disposicions de Ramon se cenyien a trobar una solució a la problemàtica que presentaven en aquell moment els dos centres que integraven la comunitat femenina de Vallbona. D'altres béns no en tenia un anacoreta que havia abandonat totes les coses terrenals per a servir en la més estricta pobresa el camí evangèlic.

\footnotetext{
${ }^{66}$ Joan Josep PIQUer 1 JOVER, Cartulari de Vallbona (1157-1665), "Boletín de la Real Academia de Buenas Letras de Barcelona“, XXXVII (1977-1978), doc. 10, pp. 80-81.
} 
Pel que fa als altres centres eremítics per ell fundats ja deurien haver quedat arranjats amb les disposicions que deuria haver donat amb anterioritat. Per això, en el seu testament, Ramon després de disposar que el seu cos fos inhumat a l'església de Santa Maria de Vallbona, passa tot seguit a ocupar-se dels centres de Vallbona i de Colobres.

La situació en aquells moments deuria ser la següent: Colobres, on s'havia concentrat la comunitat que volia seguir la forma cistercenca, s'havia consolidat ja com una abadia incipient, disposant del nombre de religioses suficients i tenint al seu front una abadessa que degué ser elegida d'entre el grup que vingué de Tulebras per tal d'ensinistrar les eremites en la nova vida cenobítica. Vallbona, de la seva banda, representava el nucli inicial al redòs del qual s'havia originat el moviment eremític encapçalat per Ramon de Vallbona i el centre administratiu del complex eremitico-cenobític, integrat per anacoretes que residien al Mas del Sant Esperit i per algunes dones que desitjoses d'abraçar la vida religiosa esperaven el moment d'ingressar a Colobres. No hi ha cap dubte que Ramon deuria tenir una major preferència i inclinació per Vallbona, el lloc on ell mateix havia començat la seva vida d'oració i penitència i on havia rebut els seus primers deixebles. La situació, però, exigia un respecte a la realitat atès que Colobres de fet s'havia convertit ja en un centre monàstic cistercenc canònicament organitzat mentre que Vallbona només ho era embrionàriament.

Amb un sentit d'estricte justícia Ramon, conscient de la realitat, advoca per una solució que hauran de prendre les pròpies interessades: com que canònicament només existeix el monestir de Colobres sotmet el convent i monges de Vallbona a l'obediència de l'abadessa de Colobres, amb la condició que aquesta no les tregui mai de Vallbona i no els hi prengui res dels béns i propietats. D'aquesta manera manté el sentit jeràrquic de Colobres tot respectant, però, la comunitat de Vallbona així com els seus béns i drets.

En el cas, però, que l'abadessa de Colobres, vulgués romandre a Vallbona, mana que les monges d'aquest lloc li prestin obediència, mentre que si es vulgués quedar a Colobres, les monges de Vallbona, queden facultades per elegir una priora sense cap mena d'impediment.

Finalment, el testament de Ramon recollia una disposició que afectava al seu germà Poculull. Aquest havia estat en molts moments la seva mà dreta; l'havia acompanyat en els seus viatges, havia fet propaganda dels seus ideals religiosos i probablement algunes persones que ingressaren a Vallbona ho feren gràcies a la tasca de proselitisme de Poculull. A ben 
segur, també, que havent enviudat, s'enrotllà com un "familiar". No és d'estranyar, doncs, que Ramon tingués un mirament i una atenció especials pel seu germà i que d'alguna manera li assegurés el seu futur com a recompensa dels seus desvels en favor de la seva causa. Per això, manà testamentàriament, que el seu germà Poculull tingués de per vida menjar i vestir a l'església de Vallbona, podent romandre aquí tant si hi ingressava com a frare com si es mantenia laic.

Al dia següent moria Ramon, en mig del dolor dels seus adeptes, i com un frare més del grup el seu cos era inhumat en el fossar annex a l'església de Santa Maria.

Aquesta església ermitana -que després rebrà el nom de Santa Maria "La Vella", per distingir-la de la monacal de Santa Maria, i que esdevindrà la parroquial del lloc atesa per un sacerdot designat pel monestir, es trobava a una distància d'uns cent metres al nord-oest de l'actual emplaçament del cenobi. Bastida al damunt d'una gran roca era la que havia donat el nom a l'indret, anomenat "Santa Maria de Vallbona". Al seu redós, aprofitant les coves i abrics naturals, havien bastit els seus primers habitacles Ramon i els altres anacoretes que havien seguit el seu missatge espiritual.

Que l'anacoreta visqué i morí amb fama de santedat està confirmat per la disposició que ben aviat prengueren els seus deixebles i pel text hagiogràfic que al cap d'uns anys fou redactat i que constitueix la Vita beati Raimundi confessoris. Quant al primer aspecte, el P. Pasqual - tot i que no ho podem corroborar amb documentació coetània- explica que l'onze de juliol del mateix any de la seva mort foren desenterrades les seves despulles i sepultades novament sota l'ara de l'altar major de l'església de Santa Maria "La Vella", essent objecte de culte públic i devoció dels anacoretes, monges i fidels de la contrada ${ }^{67}$.

Passats uns quants segles, amb motiu de l'estada a Vallbona del famós historiador de l'orde cistercenca, el P. Zapater, aquest promogué el trasllat de les seves restes a l'interior de l'església del cenobi, cerimònia que es dugué a terme el 24 de gener de 1665 . Col-locades en una urna que tenia pintat l'eremita vestit amb els hàbits del Cister, subsistí, després d'haver

\footnotetext{
${ }^{67} \mathrm{P}$. Jaime PASQual, Carta al Marqués de Capmany, obra cit. pp. 28-29.
} 
patit diverses incidències, fins els primers dies de la passada guerra civil en què, juntament amb altres objectes artístics, foren preses de les flames ${ }^{68}$.

El testament de Ramon, tal com hem apuntat, donava la possibilitat que fossin les religioses les que adoptessin en darrer terme les solucions que els hi semblessin millor.

Colobres es deuria ja haver constituït com a comunitat canònica -recordem que la seva responsable s'esmenta com a "abadessa" - mentre que Vallbona, mentre visqué Ramon aquest n'exercí les funcions que havia tingut sempre, director, responsable i guia espiritual. Ara, sense ell, les coses havien de canviar necessàriament, consolidant-se dos centres -en el cas que l'abadessa de Colobres es volgués mantenir aquí- o potenciant el de Vallbona, en el cas que volgués traslladar-se a dirigir la comunitat de la vall. Al final, fou aquesta darrera, la decisió adoptada.

Degué ser en aquestes circumstàncies quan va intervenir Berenguera de Cervera. Tal com diu l'abaciologi antic del monestir aquesta senyora, anà a Colobres i va convèncer Òria perquè es traslladés a la vall per dirigir el grup que hi havia aquí.

\section{El trasllat de l'abadessa Òria de Colobres a Vallbona}

Després de la mort de Ramon de Vallbona les religioses d'aquest lloc i de Colobres restaven facultades per seguir el camí que més els plagués. En tot cas, però, la decisió darrera estava en mans de l'abadessa qui hauria de valorar els avantatges i inconvenients que la seva adopció hauria de representar per a la comunitat.

No es conserva cap document coetani que ens confirmi que en aquesta època detentés el càrrec Òria, per bé que atès que en el testament de Ramon es parli específicament de l'abadessa de Colobres i que la primera que apareix immediatament després de la mort del fundador sigui l'esmentada senyora, suggereix que fos precisament Òria la responsable legal de la comunitat en aquell moment.

No li deuria ser fàcil a Òria prendre el determini de traslladar-se a Vallbona després d'haver ja constituït la comunitat cistercenca a Colobres,

${ }^{68}$ Josep Joan PIQUER I JOVER, Abaciologi de Vallbona (1153-1977), Santes Creus, 1978, pp. 250-251. 
ja que alguns dels seus membres, reacis ni que sigui per inèrcia a qualsevol canvi, s'hi deurien oposar. Potser ella mateixa participava inicialment d'aquest mateix criteri.

En aquesta situació d'impàs cal situar, doncs, la intervenció de Berenguera de Cervera que, tot $\mathrm{i}$ no exercir cap càrrec dins el grup vallbonenc, pel seu prestigi social era la persona més adequada per negociar amb la comunitat de Colobres. Berenguera, doncs, conscient que era la comunitat de Vallbona la que calia potenciar, sigui per la situació geogràfica, sigui per la vinculació històrica amb el lloc originari eremític, anà al monestir de Colobres $\mathrm{i}$ va convèncer Òria a traslladar-se a la vall. Així s'entendria el paper que el vell abacilogi de Vallbona assigna a Berenguera quan diu "et ivit apud Colobres et adduxit secum dominam Oriam que fuit prima abbatissa Vallisbone". No compartim, per tant, l'opinió del benemèrit historiador Piquer quan afirma que Berenguera de Cervera anà a "Tulebras d'on portà Òria ja que no tindria sentit que hagués anat a Colobres, establert a tan poca distància $i$ on les monges, segons sembla, no s'havien incorporat a cap congregació" ${ }^{\circ 9}$.

Tot i que ni les cròniques de l'època ni tampoc la documentació enregistri res d'aquests fets, l'episodi no degué ser ignorat ni pel monarca ni pels nobles veïns, que ben aviat palesaren amb donacions el reconeixement de la nova situació. En efecte, el mes de març de 1177, des de Lleida, Alfons I donava al cenobi de Vallbona i a la seva abadessa Òria la propietat que tenia a Rosea ${ }^{70}$. El mes següent, trobant-se a Tarragona, juntament amb la reina Sança, concedia a la comunitat i a l'abadessa Òria l'important privilegi d'immunitat a favor de les "seves cases, granges o cabanes", homes i ramats ${ }^{71}$.

Curiosament, aquest document l'original del qual no ha pervingut fins a nosaltres i que coneixem a través d'una còpia parcial enregistrada pel P. Pasqual en el Llibre vert, és idèntic - canviant el nom del cenobi, de

\footnotetext{
${ }^{69}$ Josep Joan PIQUER I JOVER, Abaciologi de Vallbona (1153-1977), Fundació Roger de Belfort, Santes Creus, 1978, p. 39.

${ }^{70}$ Josep Joan PIQUER I JOVER, Cartulari de Vallbona (1157-1665), "Boletín de la Real Academia de Buenas Letras de Barcelona”, XXXVII (1977-78), doc. 9, p. 80. Tot i que aquest instrument estigui datat el mes de març de 1176, cal suposar que fos abans del 25 del dit mes, de manera que correspondria a l'any seguent de l'era comuna.

"Josep Joan PIQUER I JOVER, Cartulari de Vallbona (1157-1665), "Boletín de la Real Academia de Buenas Letras de Barcelona”, XXXVII (1977-1978), doc. 12, p. 84.
} 
l'abat, el del lloc d'atorgament i el de l'escrivà- a l'adreçat a Poblet pel mateix monarca, i datat el 23 de maig de $1170^{72}$.

Aquesta circumstància suggereix la possibilitat que la comunitat vallbonenca, ja plenament establerta, coneixedora del privilegi concedit al monestir germà i de les avantatges que la seguretat reial proporcionava al patrimoni pobletà, sol-licités al monarca un document semblant, qui, de la seva banda, acceptà la petició fent-la expedir pel seu escrivà Guillem de Bassa.

El trasllat d'Òria a Vallbona deuria motivar, d'altra banda, l'inici de les primeres construccions monàstiques, ja d'acord amb el model cistercenc, si bé hagué d'adaptar alguns aspectes a la situació del terreny, fet que li ha donat en certa manera la seva originalitat. Resulta avui per avui molt difícil d'identificar la part del monestir bastit en aquest període inicial de l'abadiat d'Òria $^{73}$. Només amb l'ajut de l'Arqueologia, hom podrà esbrinar correctament aquella part del cenobi que es bastí durant el període de temps que el governà Òria. provisional.

\section{LA VISITA I EL SOJORN DELS MONARQUES CATALANS ALFONS I SANÇA A VALLBONA (FEBRER-MARÇ DE 1178)}

Cal situar en aquests darrers anys de la dècada dels setanta l'interès específic dels monarques catalans per l'incipient monestir de Vallbona, interès que implicarà fins i tot la visita, amb l'estada d'uns dies, - probablement dues setmanes, entre final de febrer i mitjant març de 1178-, dels sobirans al cenobi urgellenc ${ }^{74}$.

\footnotetext{
${ }^{72}$ Agustí ALTISENT, Diplomatari de Santa Maria de Poblet. Volum I. Anys 960-1177. Generalitat de Catalunya, Barcelona, 1993, doc.375, pp. 284-285.

${ }^{73} \mathrm{G}$. Gonzalvo opina, seguint la tradició historiogràfica de Vallbona, que la part romànica de l'església es degué iniciar a bastir entre 1163-1177 (Gener GonZaLvo I Bou-Josep Maria SANS I TRAVÉ, Vallbona. Guia histórico-artística, Lleida, 1998, p. 104). D'altra banda, Jordi Camps, en estudiar els elements romànics de les ales oriental i meridional del claustre del monestir, que deurien ser els més antics, els fa datar de començament del segle XIII (Jordi CAMPS I SÒRIA, Notes sobre l'escultura del claustre de Vallbona de les Monges, a "Miscel-lània en homenatge a Joan Ainaud de Lasarte", I, Montserrat, 1998, pp. 237-243).

${ }^{74}$ Josep Joan PIQUER I JOVER, Abaciologi de Vallbona (1153-1977), Santes Creus, 1978, pp. 49-52.
} 
Dues fonts coetànies enregistren el sojorn reial a Vallbona. L'una és la declaració de fra Guillem Sabater, monjo de Poblet que, arran dels luctuosos successos esdevinguts amb motiu de l'ocupació de la partida del Codós per certs homes de l'Espluga Sobirana que atacaren i feriren alguns frares de Poblet que hi treballaven, exposà que "ell va veure i escoltar que quan el rei va passar per aquest lloc de camí cap a Vallbona, va manar personalment que els frares de Poblet entressin en possessió del Codós"75.

L'altra font que prova l'estada vallbonenca és la datació d'un acord entre el rei Alfons i els cavallers del castell de Mor, enregistrat en un document de la cancelleria reial. El seu escatocol diu així: Actum est hoc apud Sanctam Mariam de Valibona, amb expressió només de l'any de l'Encarnació, que correspon al $1178^{76}$.

Diversament del que es pot suposar, quan s'esdevingué la visita dels sobirans al monestir, no es disposava encara de cap construcció monàstica acabada, per bé que algunes estructures tot just s'havien iniciat a bastir. Per tant, a ben segur que els actes protocolaris que exigien la presència del sobirà es van celebrar a l'església de Santa Maria la Vella, convertida per uns dies en seu de la cort reial.

La visita resultà especialment positiva per al cenobi l'abadessa del qual sabé atreure l'atenció del rei i la reina en favor de la comunitat. El primer fruit tangible del sojorn del monarca va ser el registrat en un document, tot i que l'original s'ha perdut, recollit en el Llibre vert del P. Pasqual $^{77}$. Es tracta d'un instrument molt curiós pel qual la reina Sança fa patent tres coses: primera, que va comprar per 500 sous el lloc de Vallbona a les religioses que vivien allí; segon, que després d'haver-lo adquirit, tot seguit el donà a les dites senyores per tal que hi edifiquessin una casa $o$ monestir on duguessin vida regular dedicada a servir devotament a Déu; i finalment, que la reina es comprometia a concedir els béns necessaris que proporcionessin menjar i vestir per a la comunitat.

\footnotetext{
${ }^{75}$ [J. PONS I MARQUÈs] Cartulari de Poblet. Edició del manuscrit de Tarragona, Barcelona, 1938, doc. 53, p. 27. Vegeu també Agustí ALTISENT. Un poble de la Catalunya Nova els segles XI i XII. L'Espluga de Francolí de 1079 a 1200, "Anuario de Estudios Medievales", 3 (1966). pàgs. 164-165.

${ }^{76} \mathrm{~F}$. MIQUel RosSELL, Liber Feudorum Maior. Cartulario real que se conserva en el Archivo de la Corona de Aragón, vol. I, Barcelona, 1945, doc. 167, pp. 176-177.

${ }^{77}$ Josep Joan PIQUer I JOVER, Cartulari de Vallbona (1157-1665), "Boletín de la Real Academia de Buenas Letras de Barcelona”, XXXVII (1977-1978), doc. 14, p. 85.
} 
De la lectura, doncs, d'aquest document, que portava només la signatura de la reina, se'n desprèn que Sança amb l'adquisició del lloc de Vallbona mitjançant cinc-cents sous i la donació immediata a les religioses pretenia, per una banda, ser la fundadora del monestir - d'aquí hauria de venir el títol de reial a l'abadia vallbonenca, no del fet que hi fos inhumada la reina Violant-, i, d'altra banda, ser la seva impulsora atès que li lliurava la suma dels 500 sous i es comprometia a proporcionar rendes que garantissin el sosteniment de la comunitat.

El sojorn dels monarques a Vallbona tingué una certa ressonància en el país i donà peu al trobador provençal Girault del Luc, enemic declarat del rei Alfons, per acusar-lo d'haver abusat de tres monges. En un sirventés el poeta posa en boca de Marquesa de Cabrera aquestes paraules:

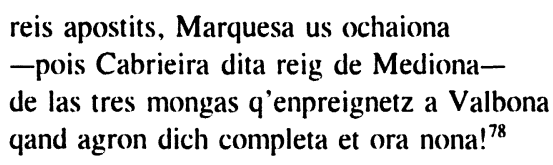

Tot i que per aquell temps diverses dones joves integraven l'incipient comunitat vallbonenca, l'afirmació d'aquest trobador s'ha de reputar com a falsa i destinada a difamar la persona del monarca. Difícilment es podien donar aquests fets sacrílegs amb la presència allí mateix de la reina, i en el cas d'haver-se donat, el rei no hauria continuat afavorint la comunitat ni les monges haurien acceptat amb bon ànim el fruit de la generositat del monarca.

\section{LA DONACIÓ D'UNA TORRE I D'UNES TERRES AL TERME DE LA CIUTAT DE LLEIDA \\ (26 DE MARÇ DE 1178)}

I EL PROJECTE DE LA FUNDACIÓ D'UN NOU MONESTIR

Arran de la visita reial al centre cenobític que s'anava constituint al redòs de Vallbona Alfons I s'adonà de l'interès que aquella incipient

\footnotetext{
${ }^{78}$ M. DE RIQUER, La poesia d'Alfons, dit el Cast, a "VII Congreso de Historia de la Corona de Aragón. Ponencias", vol. I, Barcelona, 1962, p. 139. Vegeu també Josep Joan PIQUER I JOVER, Abaciologi de Vallbona (1153-1977), Santes Creus, 1978, p. 51.
} 
comunitat podria representar per al país de cara a organitzar una futura xarxa de monestirs femenins impulsats pel cenobi urgellenc. De la mateixa manera que poc temps abans el monarca havia confiat a Poblet la seva expansió monàstica cap a terres valencianes concedint el mes de febrer de 1176 el lloc de Cepolla, situat a les Espanyes, prop de la ciutat de València, perquè el cenobi de la Conca hi constituís, quan en fos conquerit, un monestir amb capacitat per a cent preveres ${ }^{79}$, encomanava també a Vallbona la fundació d'una nova abadia femenina a la ciutat de Lleida ${ }^{80}$.

En efecte, al cap de pocs dies d'haver abandonat Vallbona i mentre es trobava a Saragossa, Alfons I donava al nostre monestir, a Òria i a les religiosos que hi vivien una torre en el terme de la ciutat de Lleida per tal que hi fos construïda una abadia de monges cistercenques. A més, concedia un home que tenia a Lleida, anomenat Ramon d'Aragó, amb totes les seves propietats, perquè fos del monestir. L'acte degué tingué una certa solemnitat perquè, a més dels sobirans, hi foren presents els nobles més encimbellats de les terres ponentines: Guillem de Cervera i Guerau de Jorba, germans, Bernat i Guillem d'Anglesola, Pere de Bellvís i Berenguer de Boixadors, a més del degà barceloní, Ramon de Caldes.

L'esmentada torre comportava també unes propietats que tenia a Lleida l'església de Girona. El conjunt de torre i terres afrontava amb el riu Segre i amb la torre que havia estat de Berenguer Arnau d'Anglesola, la serra d'Alcolea i la torre que havia estat d'Arnau de Rufaca. La concessió, però, no era només de l'edifici i de les terres, sinó que, atès que per al bon funcionament d'un monestir era bàsic poder disposar de l'aigua suficient per a les necessitats domèstiques i també per al conreu de l'hort o terra annexa al centre cenobític d'on es treia una part important de dels productes que consumia diàriament la comunitat, implicà el gaudiment de l'aigua necessària per al futur monestir, sense que estiguessin obligades les religioses a cap pagament per la seva utilització ni tan sols les despeses de reparació de la sèquia.

No deixa de ser sorprenent que fos en els moments inicials de la constitució del monestir de Vallbona quan Alfons I pengué aquesta determinació quan el principal objectiu del cenobi fos la consolidació de la

\footnotetext{
${ }^{79}$ Agustí Altisent, Diplomatari de Santa Maria de Poblet. Volum I. Anys 960-1177, Generalitat de Catalunya, Barcelona, 1993, doc. 548, p. 404.

${ }^{80}$ Josep Joan PIQUER I JOVER, Cartulari de Vallbona (1157-1665), "Boletín de la Real Academia de Buenas Letras de Barcelona”, XXXVII (1977-1978), doc. 15, pp. 85-86.
} 
pròpia comunitat. El monarca, però, deuria veure els membres vallbonins animats i amb aptitud suficient per tirar endavant el seu projecte monàstic. El nou encàrrec, ni que en aquells moments fos feixuc, deuria estat avalat per l'ànim i l'empenta d'aquelles religioses que, sota la direcció d'Òria, es trobaven amb capacitat no només per consolidar el propi cenobi sinó també per respondre positivament a la nova iniciativa que el monarca els hi proposava.

De fet, la concessió reial havia d'actuar d'esperó en el si de la comunitat urgellenca, de manera que les monges tinguessin un nou objectiu per assolir. Això els comportaria la consciència que cảlia apressar-se en l'organització i consolidació del propi monestir a fi i efecte que després poguessin dur a bon terme amb èxit la fundació del nou cenobi.

Quatre anys abans el mateix monarca, interessat en vincular les religioses bernardes a la ciutat de Lleida, havia donat, tal com hem esmentat més amunt, la plaça del pastisser Ponç, que abans de la reconquesta de la ciutat havia pertangut al cantarer Boachar i als seus nebots ${ }^{81}$. Era el mes d'octubre de 1174. En aquesta època era massa aviat perquè el cenobi pogués fer algun tipus de fundació monàstica a la ciutat. La seva actuació es deuria cenyir exclusivament a percebre les rendes que aquesta propietat deurien proporcionar a la comunitat.

Vallbona no trigà massa temps en assolir el compliment del projecte encomanat pel monarca car pocs anys després, el 1204, el cenobi urgellenc fundà a la ciutat de Lleida el de Sant Hilari amb religioses procedents del monestir mare ${ }^{82}$. Entre les monges vallbonines que inicaren la vida cenobítica a Sant Hilari s'hi comptaven Geralda de Cervelló i Sibila d'Urg.

Abans de prendre aquesta ressolució, el monestir havia aconseguit disposar d'un patrimoni suficient de manera que la futura comunitat es pogués autoabastar. Primer, el mateix any 1178, el mes d'agost, les religioses urgellenques representades per l'abadessa Òria Ramirez, rebien d'una persona molt vinculada al monarca, Bernat de Caldes, atès que n'era el seu notari, un honor a la ciutat de Lleida, encaminat a potenciar el futur

\footnotetext{
${ }^{81}$ Josep Joan PIQUer I JOVER, Cartulari de Vallbona (1157-1665), "Boletín de la Real Academia de Buenas Letras de Barcelona”, XXXVII (1977-1978), doc. 7, pp. 78-79.

${ }^{82}$ José LladonosA, El Real Monasterio de Santa Maria de Vallbona (1157-1957), Lérida, 1957, pp. 109-112.
} 
del nou centre monàstic ${ }^{83}$. Al cap de cinc anys, el mes de setembre de 1183, novament Alfons I, de Lleida estant, i en presència de diversos clergues dels seus regnes, com ara el bisbe Berenguer de Lleida, el bisbe Esteve d'Osca, el bisbe Pere de Saragossa i el bisbe Tomàs de Tarassona, concedia al monestir de Vallbona i a la seva abadessa Òria Ramírez la torre anomenada de Serralada ${ }^{84}$. Aquesta torre es trobava al costat de l'honor que el mateix monarca havia concedit a Pere de Besora, i afrontava per llevant amb la clamor d'Almacelles, pel migdia amb el camí vell i també tenia com a fitació el camí nou que anava de Lleida a Montsó.

L'estada dels monarques a Vallbona, finalment, estengué arreu del país la bona fama d'unes dones fortes que, abandonant el segle, volien dedicar-se a la vida religiosa i d'oració, d'acord amb els principis monàstics que propugnava Citeaux. Si abans, els benefactors del grup eremític se cenyien gairebé en exclusiva als senyors i cavallers de l'entorn més immediat que concedien terres i drets a tocar al lloc de Santa Maria, a partir del sojorn dels reis el centre cenobític acreixerà el seu patrimoni gràcies a les donacions de nobles i fidels de tot el territori. D'altra banda, també, Vallbona es convertirà a partir d'aquest moment en un dels principals centres d'atracció i destinació religiosa de la Catalunya Nova per part de les filles de la noblesa amb inquietuds espirituals. El pas profund que representà el canvi de vida eremítica a cenobítica possibilità que Vallbona pogués aglutinar en el seu si les peticions d'ingrés de nous membres, tot adequant a les necessitats sorgides les estructures adients i, per consegüent, iniciant la construcció d'aquells edificis monàstics imprescindibles per a la comunitat.

Les responsables de la comunitat, de la seva banda, no descuraren d'incrementar el seu patrimoni, especialment el situat a tocar al terme del cenobi. Un dels nobles de la comarca que posseïa drets al costat de Vallbona era Guillem d'Aguda, feudatari dels Cardona, senyors eminents de Maldà i d'altres llocs de la contrada. Precisament foren els Aguda, representats per Pere i la seva dona Ermessèn, juntament amb els seus fills Guillem, Bernat i Ramon, i el germà de Pere, Ramon Conill i la seva dona Ermessèn, els que inicialment donaren el terme de Vallbona a l'eremita Ramon el 9 d'octubre

\footnotetext{
${ }^{83}$ Josep Joan PIQUer I JOVER, Cartulari de Vallbona (1157-1665), "Boletín de la Real Academia de Buenas Letras de Barcelona”, XXXVII (1977-1978), doc. 16, p. 87.

${ }^{84}$ Josep Joan PIQUER I JOVER, Cartulari de Vallbona (1157-1665), "Boletín de la Real Academia de Buenas Letras de Barcelona”, XXXVII (1977-1978), doc. 20, pp. 90-91.
} 
de $1157^{85}$, i al cap de pocs anys, el 26 de juny de 1169, el mateix Pere, juntament amb el seu fill Guillem i la seva dona Sança, concedia a Vallbona un hort, situat a Sant Martí i el lloc de Llorenç, que representà una de les primeres propietats que adquirí Vallbona fora del terme monàstic ${ }^{86}$.

Aquest mateix Guillem d'Aguda, passats un anys, havia de palesar novament el seu afecte vers el monestir cistercenc, concedint el mes d'abril de 1180 la seva pròpia filla Romana perquè abracés la vida religiosa: Amb motiu de l'esmentat ingrès en el cenobi, Guillem confirmava la cessió dels drets que tenia en el terme de Vallbona i donava al monestir tots els drets que posseïa al Vilet - anomenat Villa Magni Honoris o Vilamanyanor-i la meitat d'un alou que tenia a Sant Martí, situat al costat de l'hort que ja hi posseïen les monges, així com els molins anomenats del Vinyet $i$ un diumenge ${ }^{87}$.

La darrera concessió fou feta davant Sandine, abbatisse, fet que ha motivat que Piquer s'hagi inclinat per incloure en l'abaciologi oficial del monestir el nom d'aquesta abadessa, que ocuparia l'abadiat entre la primera (març de 1176 [1177]-1180) ${ }^{88}$ i segona prelatura d'Oria (8 de febrer de $1181[1182]-\ldots 13$ de febrer de $1184[1185] \ldots)^{89}$. A nosaltres ens consta creure en l'existència d'aquesta abadessa anomenada Sandina el nom de la qual no és recollit en el primer abaciologi del monestir que després d'Òria enregistra Ermessenda de Rubió com a suceesora ${ }^{90}$. Potser cal pensar que Sandina fou simplement un apel·latiu pel qual era coneguda també Òria, de la mateixa manera que Ermessenda de Rubió fou coneguda amb el nom de

\footnotetext{
${ }^{85}$ Josep Joan PIQUER I JOVER, Cartulari de Vallbona (1157-1665), "Boletín de la Real Academia de Buenas Letras de Barcelona”, XXXVII (1977-1978), doc. 3, p. 76.

${ }^{86} J o s e p$ Joan PIQUER I JOVER, Cartulari de Vallbona (1157-1665), "Boletín de la Real Academia de Buenas Letras de Barcelona", XXXVII (1977-1978), doc. 5, pp. 77-78. p. 54 .

${ }^{87}$ Josep Joan PIQUER I JOVER, Abaciologi de Vallbona (1153-1977), Santes Creus, 1978,

${ }^{88} \mathrm{Amb}$ més rigor, l'inici de l'abadiat d'Òria s'hauria d'ajornar un any, ja que el document datat el març de 1176 correspon al 1177 de l'era comuna.

${ }^{89}$ Josep Joan IQUER I JOVER, Abaciologi de Vallbona (1153-1977), Santes Creus, 1978, pp. 46-56. Així mateix, l'inici de la segona prelatura d'Oria s'hauria d'ajornar igualment un any, és a dir, el 8 de febrer de 1182 , atès que el document que enregistra la donació de Pere de Bellvís està datat per l'any de l'Encarnació, que correspon al 1182 de l'era comuna. El mateix podem dir respecte del final del seu abadiat ja que el document del mes de febrer de l'any 1184 de l'Encarnació correspon al 1185 de l'era comuna.

${ }^{90}$ Josep Joan PIQUer I Jover, Cartulari de Vallbona (1157-1665), "Boletín de la Real Academia de Buenas Letras", XXXVII (1977-1978), Apèndix, p. 108.
} 
"Boscana". No sambem a quin fet respondria, en el cas que fos tal com proposem, l'origen d'aquest apel-latiu d'Òria.

\section{L'OBRA DE L'ABADESSA ÒRIA}

Vallbona tingué la sort de disposar en aquells moments de tant d'interès per al seu futur de dos personatges que complementaren les seves qualitats en benefici de la institució. En primer lloc, Berenguera de Cervera, la dama que a través de les seves vinculacions i coneixences amb els elements més dinàmics de la societat sabé difondre a la monarquia i la noblesa els valors del nou monestir cistercenc.

L'abadessa Òria Ramírez és el segon personatge providencial de què gaudí Vallbona per aquest mateix temps. Aquesta prelada representa el seny i la capacitat organitzativa. Té, primer, l'encert de traslladar la comunitat a Vallbona, de connectar de manera positiva amb la reina Sança i el propi monarca i sobre tot de decidir la construcció d'uns edificis monàstics amb visió de futur, és a dir, amb la capacitat suficient perque en el monestir hi pogués habitar una comunitat en expansió. Finalment, a Òria s'ha d'atribuir la consolidació del canvi de les bases econòmiques de Vallbona.

Per a cobrir les necessitats vitals d'un grup eremític - ja ho hem dit-calien pocs recursos econòmics, de manera que amb l'explotació de les terres i boscos integrants inicialment de l'alou de Santa Maria n'hi deuria haver més que suficient. També els components del grup ermità deurien ser molt pocs i la sàbia visió dels responsables evitaria rebre més gent de la que es pogués assumir. La vida cenobítica en canvi, ni que fos emmarcada en l'austeritat i pobresa del Cister, comportava un nivell d'exigències molt superior i també implicava unes despeses més grans.

Per tot això, Vallbona necessità una ampliació de les seves bases econòmiques ja que amb els recursos inicials no n'hi havia prou ni per engegar les construccions previstes, que s'havien de fer exclusivament amb la contractació de grups d'operaris especialitzats en aquests tipus d'obres - diversament del que s'esdevenia amb els altres monestirs cistercencs de Poblet i Santes Creus, en què una part important d'aquest tipus de treball era assumit pels monjos - ni tampoc per alimentar la cada vegada més nombrosa comunitat. No és d'estranyar, per consegüent, que a final dels anys setanta i al llarg de la dècada següent hom trobi un augment important del patrimoni 
vallbonenc. Seran les rendes procedents de la seva explotació les que s'esmerçaran bàsicament en l'atenció d'aquestes noves necessitats.

El sistema d'explotació ja no serà només el directe, cenyit al domini senyorial estricte del monestir de Vallbona i dut a terme amb la col-laboració d'antics eremites que van optar per restar al redós de la comunitat i sobre tot d'alguns donats que s'aixoplugaven en el cenobi. Les propietats que pervingueren al monestir, tot i que algunes es trobaven a tocar -com la del Vilet, concedida l'abril del 1180 per Guillem d'Aguda amb motiu de l'ingrés de la seva filla Romana ${ }^{91}$, o el castell i terme de Llorenç, concedit a la comunitat el 8 de febrer de 1182 pel noble Pere de Bellvís amb motiu de ferse familiar del monestir ${ }^{92}$ - la seva major part es trobaven llunyanes $i$ s'hagueren de concedir a emfiteutes que per la seva tinença pagaren un cens anual a la comunitat. En són un bon exemple la finca situada al terme de Barbens que el 27 de novembre de 1177 donaren al monestir Ramon de Tarroja i la seva esposa Gaia ${ }^{93}$, o l'honor que l'agost del 1178 concedí a Lleida Bernat de Caldes, un dels escrivans del rei Alfons $\mathrm{I}^{94}$, o les tres jovades de terra que pertanyents a la torre de Serralada, situada dins la ciutat de Lleida, concedí el monarca el setembre de $1183^{95}$.

Finalment, Òria fou la impulsora de la vinculació de laics al monestir a través de la "familiaritas". Aquesta institució jurídica permetia la incorporació de seglars dels dos sexes a la comunitat, algunes vegades ingressant com a donats al monestir i duent a terme tasques de col laboració, com podien ser les domèstiques o fins i tot les atanyents a l'explotació de les terres, els molins i els ramats de bestiar, i d'altres, tot romanent en el segle, concedint un bé en el moment de formalitzar la "familiaritas" o comprometent-se a lliurar unes rendes anuals o bé una propietat després del traspàs. El monestir, en recompensa d'aquesta generositat, acceptava al "familiar" com

\footnotetext{
${ }^{91} J o s e p$ Joan Piquer I Jover, Cartulari de Vallbona (1157-1665), "Boletín de la Real Academia de Buenas Letras de Barcelona”, XXXVII (1977-1978) doc. 17, p. 87.

${ }^{92}$ Josep Joan PiQuer I Jover, Cartulari de Vallbona (1157-1665), "Boletín de la Real Academia de Buenas Letras de Barcelona”, XXXVII (1977-1978) doc. 19, pp. $89-90$ (datat erròniament el 1181).

${ }^{93}$ Josep Joan Piquer I Jover, Cartulari de Vallbona (1157-1665), "Boletín de la Real Academia de Buenas Letras de Barcelona“, XXXVII (1977-1978), doc. 13, pp. 84-85.

${ }^{94} J$ Josep Joan PIQUer I JOVER, Cartulari de Vallbona (1157-1665), "Boletín de la Real Academia de Buenas Letras de Barcelona”, XXXVII (1977-1978), doc. 16, p. 87.

${ }^{95}$ Josep Joan PIQUer I JOVER, Cartulari de Vallbona (1157-1665), "Boletín de la Real Academia de Buenas Letras de Barcelona”, XXXVII (1977-1978), doc. 20, p. 90.
} 
a partícep dels beneficis espirituals i oracions de la comunitat i s'obligava a tractar-lo el dia de la seva mort com un frare o monja cistercenc, fent celebrar els mateixos oficis eclesiàstics i sufragis per l'ànima del difunt que feien per a un membre de la comunitat.

Alguns dels que ingressaren com a "familiars" a Vallbona eren gent de les poblacions veïnes, que no deurien tenir cap patrimoni per oferir, que cercaren en el monestir la manera més adequada per a subsistir, i que, com a donats, aportaren simplement el seu treball a canvi també del manteniment per part del cenobi. Aquests representaven el grup dels anònims l'ingrés dels quals no ha quedat reflectit en la documentació vallbonenca, ja que no pressuposava cap donació de patrimoni, no va merèixer la confecció del corresponent instrument. Alguns, per bé que en comptades ocasions, sigui perquè acompanyaven els responsables del cenobi, sigui per altres circumstàncies, apareixen com a testimonis dels documents relatius al monestir. En definitiva, foren aquests "familiars" una mà d'obra barata que també, a la seva manera, contribuí a la consolidació i expansió del monestir urgellenc.

L'ingrés, per contra, a la "familiaritas" de gent d'alcúrnia tenia un caire molt divers i de l'acte, atès que comportava la cessió d'un bé, se'n redactava el corresponent instrument. A més, se celebrava amb la solemnitat que exigia la noblesa o el nivell social de l'aspirant, no mancant-hi la presència dels seus senyors, vassalls i amics. N'és un bon exemple l'esmentat Pere de Bellvís, que quan el 8 de febrer de 1182 entrà en la germandat vallbonenca, hi assistiren, a més de l'abadessa Òria i els altres càrrecs de la comunitat, les seves germanes Ermessèn i Anglesa, i els nobles Guillem i Ramon d'Anglesola.

\section{LA COL·LABORACIÓ \\ DE Berenguera de CERvera o D'ANGlesola}

Hem esmentat més amunt el paper important que Berenguera de Cervera desenvolupà en els inicis $\mathrm{i}$ els primers anys del monestir de Vallbona. Aquesta dama representà, tal com diu l'abaciologi del cenobi, la primera senyora noble que ingressà a Vallbona.

$\mathrm{Cal}$ pensar que fou degut a les seves gestions principalment que els monarques visitessin Vallbona i que, a més, bona part de les donacions que rebé en aquesta època el cenobi fossin impulsades per Berenguera. La seva ascendència social $i$ aquestes activitats donaren a Berenguera un especial 
prestigi dins la pròpia comunitat. L'agraïment de la comunitat per aquesta confraressa seria encara més clar quan, després de la seva mort, Vallbona demanarà i obtindrà el 1225 del Capítol General de Citeaux la celebració d'un aniversari per tal de commemorar amb solemnitat el dia del seu traspàs ${ }^{96}$.

Les relacions de Berenguera amb el cenobi s'iniciaren ben aviat, en temps encara del fundador Ramon de Vallbona. En efecte, quan el mes d'octubre de 1173 Gombau de Talarn professava com a religiós a Santa Maria de Poboleda en mans de l'eremita Ramon, tot concedint unes propietats que posseïa al terme de Verdú, confirmaven la donació Berenguer Arnau d'Anglesola, i els seus fills Guillem i Berenguera de Cervera ${ }^{97}$. Aquesta dona feia poc que havia quedat vídua de Guillem de Cervera. Degué ser a partir d'aquesta nova situació personal que Berenguera dedicà una part de la seva activitat a potenciar la incipient comunitat que feia ben poc temps que havia estat acceptada per Citeaux.

El P. Pasqual en la seva Carta al Marqués de Capmany s'ocupa de demostrar el paper que aquesta dama tingué en la fundació del monestir. Al llarg de les pàgines que precedeixen ja hem indicat que el veritable fundador del cenobi fou l'eremita Ramon i hem intentat posar al lloc que li pertoca Berenguera de Cervera.

L'autor de l'abaciologi, Piquer i Jover, també dedica unes pàgines de la seva obra a glossar la figura d'aquesta dama a la que qualifica de "cofundadora de Vallbona"98. Jo mateix recentment tot referint-me a aquest personatge per palesar la seva influència en l'eixamplament del patrimoni del monestir a Preixana, he precisat alguns aspectes de la seva biografia i que segueixo fonamentalment ${ }^{99}$.

Filla de Berenguer Arnau d'Anglesola, primer senyor de Bellpuig, maridà vers el 1164 Guillem III de Cervera, fill de l'homònim Guillem II de

\footnotetext{
${ }^{96}$ Josep Joan PIQUer I Jover, Cartulari de Vallbona (1157-1665), “Boletín de la Real Academia de Buenas Letras de Barcelona”, XXXVII (1977-1978), doc. 24, p. 93.

${ }^{97}$ Agustí Altisent, Diplomatari de Santa Maria de Poblet. Volum I. Anys 960-1177, Generalitat de Catalunya, Barcelona, 1993, doc. 470, p. 352. $38-40$.

${ }^{98}$ Josep Joan PIQUeR I Jover, Abaciologi de Vallbona (1153-1977), Santes Creus, 1978, pp.

"9osep Maria SANS I TRAVÉ, La carta de franquicia de Preixana (l'Urgell) atorgada pel monestir de Vallbona (11 d'agost de 1228), a "Miscel-lània Àngel Fàbrega” |“Analecta Sacra Tarraconensia”, 71 (1998)], pp. 757-783.
} 
Cervera, nét aquest darrer de Guillem Dalmau i germà de Guerau de Jorba- ${ }^{100}$. Aquest matrimoni entroncava tres de les famílies més importants de la Catalunya de meitat del segle XII - Angesola, Cervera i Jorba-. Amb motiu de la seva celebració Berenguer Arnau d'Anglesola concedia a la seva filla Berenguera i al seu marit Guillem de Cervera el castell i vila de Verdú $^{101}$. Després de la mort d'aquest darrer i de restar vídua el 1172, la seva relació amb la comunitat de Vallbona s'accentuà fins que hi ingressà com a monja cistercenca.

A partir d'aquest moment la situació de Berenguera dins el monestir serà sempre d'una certa preeminència confirmada pel fet que sovint en les donacions adreçades al cenobi apareix el seu nom darrere de l'abadessa $i$ davant dels altres membres de la comunitat. Així, per exemple, quan el 8 de febrer de 1182 Pere de Bellvís concedeix al monestir el lloc de Llorenç, ho fa a l'abadessa Òria i a Berenguera de Cervera, a més de Berenguera d'Òdena $\mathrm{i}$ les altres religioses ${ }^{102}$. També quan el 13 de febrer de 1185 Jovària $\mathrm{i}$ el seu fill Guillem de Tàrrega donen Guillema, la seva filla $\mathrm{i}$ germana, respectivament, al monestir perquè en sigui religiosa, ho fan en mans de l'abadessa Òria $\mathrm{i}$ de Berenguera de Cervera ${ }^{103}$. A començament de la centúria següent, el 19 de juny de 1203, quan Pere de Tàrrega concedia al cenobi els drets que tenia en la senyoria de Preixana Berenguer Arnau de Sanahuja, la donació era feta davant l'abadessa Ermesenda de Rubió i Berenguera de Cervera ${ }^{104}$.

Amb tot Berenguera gaudi durant la seva vida d'una certa llibertat de disposició dels seus béns al segle $\mathrm{i}$, a més, participà sovint en la seva gestió. Això podria suggerir que potser Berenguera canònicament no

\footnotetext{
${ }^{100}$ Sobre el parentesc entre Guerau de Jorba i Guillem de Cervera, vegeu Agustí ALTISENT, Seguint el rastre de Guerau de Jorba i el seu llinatge, "Aplec de Treballs del Centre d'Estudis de la Conca de Barberà” 1(1978), Montblanc, pp. 42 i 54.

${ }^{101}$ Agustí Altisent, Diplomatari de Santa Maria de Poblet. Volum I. Anys 960-1177, Generalitat de Catalunya, Barcelona, 1993, doc. 258, pàg. 205. Sobre els precedents d'aquest lloc vegeu Prim BERTRAN I RoIGÉ, Noves aportacions sobre la repoblació de Verdú en el centenari de la seva carta de franquicia (1184-1984), Institut d'Estudis Ilerdencs, Lleida, 1984, $17 \mathrm{pp}$.

102Josep Joan PIQUer I JOVER, Cartulari de Vallbona (1157-1665), “Boletín de la Real Academia de Buenas Letras de Barcelona", XXXVII (1977-1978), doc. 19, pp. $89-90$ (on està datat erròniament el 1181)

${ }^{103}$ Josep Joan PIQUer I Jover, Cartulari de Vallbona (1157-1665), "Boletín de la Real Academia de Buenas Letras de Barcelona”, XXXVII (1977-1978), doc. 21, p. 91. 61-62.

${ }^{104}$ Josep Joan PIQUER I Jover, La baronia de Vallbona (Notes d'estudi), Lleida, 1981, pp.
} 
professà la vida religiosa sinó simplement s'adherí com a protectora a la incipient comunitat vallbonenca, fent-hi estades sovintejades i abandonant el monestir quan els afers civils ho requerien. Així el 18 de setembre de 1184, juntament amb els seus fills Guillem IV de Cervera i Eliarda concedia als veïns de Verdú l'exempció de l'exòrquia i del terç senyorial de les vendes de les cases amb la condició que les edifiquessin al pla que hi havia davant del castell ${ }^{105}$. A la dècada següent, el 1192 , juntament amb l'esmentat fill Guillem IV, concedia als habitants de Verdú cent astes de terra situades a la seva reserva senyorial, sota el cens d'una mujada de blat anual ${ }^{106}$.

Una de les darreres actuacions degudes probablement a la influència de Berenguera de Cervera vers el monestir de Vallbona fou la venda de Preixana per part del seu fill Guillem IV de Cervera el 9 d'agost de 1227, acte que es materialitzà quan la mare ja havia finat ${ }^{107}$.

\section{RÉSUMÉ}

À partir d'une relecture des premiers documents relatifs au monastère cistercien de Vallbona, nous pouvons étudier ses origines érémitiques mixtes - d'hommes et de femmeset la personnalité et la tâche de son fondateur, qui fût promoteur aussi même, d'autres centres à la Nouvelle Catalogne, les terres récemment conquises aux sarrasins. En 1171 la communauté fût incorporée à Cîteaux, ce qui lui comporta un gran prestige social spécialement après la visite des monarques catalans (février-mars 1178) qui ont favorisé le nouveau monastère avec la concession de privilèges et donations de terres et propriétés.

Nous étudions, finalement, le rôle développé par l'abbesse Òria, arrivée du monastère cistercien de Tulebras (Navarra) pour instruire la nouvelle communauté- et de la noble Berenguera de Cervera, une des bienfaitrices plus importantes du monastère.

\footnotetext{
${ }^{105}$ José Ma FonT RiUS, Cartas de población y franquicia de Cataluña, I. Textos, MadridBarcelona, 1969, doc. 174, pp. 241-242.

${ }^{106} \mathrm{~J}$ osep $\mathrm{M}^{\mathrm{a}}$ FONT RIUS, Carts de población y franquicia de Cataluña, II, Madrid-Barcelona, 1983, doc. 398, pp. 688-689.

${ }^{107}$ Josep Maria SANS I TRAVÉ, La carta de franquícia de Preixana (L'Urgell) atorgada pel monestir de Vallbona (11 d'agost de 1228), "Analecta Sacra Tarraconensia", 71 (1998), ("Micel.lània Ângel Fàbrega”), pp. 771-772. Sobre la personalitat de Guillem IV de Cervera, vegeu Gener Gonzalvo i Bou-Manel Salas I FlotaTS, Guillem IV de Cervera, cavaller i monjo de Poblet, "Anuario de Estudios Medievales", 28 (1998), pp. 405-418.1
} 


\section{SUMMARY}

After reviewing the oldest documents related to the Cistercian monastery of Vallbona, this article analyzes its mixed - men and women- eremitic origin and the task and personality of its founder Ramon, who was also a promoter of other settlements in the Catalunya Nova (the lands recently conquered from the Muslims).

In 1171 the community was incorporated to Cîteaux. As a consequence of that, it gained social prestige, which was increased after the visit of the Catalan king (FebruaryMarch 1178) who supported the monastery with the concession of privileges and donations of lands and properties.

Finally, this article studies the role played by abbess Òria, who came from the Cistercian monastery of Tulebras (Navarra) to instruct the new community, and by the noble Berenguera de Cervera, who was one of the most important benefactress of the abbey. 